\title{
Transparencia y riesgo reputacional en las políticas públicas de Estado
}

\author{
Dra. Ana Tomás López| ana.tomas@protocoloimep.com
}

Instituto Mediterráneo de Estudios de Protocolo

\author{
Palabras clave \\ Modernidad líquida; Políticas públicas; Riesgo \\ Reputacional; Transparencia; Corrupción. \\ Sumario \\ 1. Introducción. 2. Objetivos. 3. Metodología. 4. \\ Resultados del análisis, en el marco de la sociedad \\ "líquida" de Bauman. 4.1. De las políticas públicas de \\ Estado en España. 4.2. De la percepción de la \\ corrupción y la actividad política. 4.3. De la gestión del \\ riesgo reputacional. 5. Discusión en torno a algunas \\ propuestas de cambio. 6. Conclusiones. 7. Bibliografía. \\ 8. Notas
}

\begin{abstract}
Resumen
La metáfora de la liquidez propuesta por Bauman constituye el reflejo de una sociedad cada vez más globalizada, donde el régimen de producción industrial ha impregnado todo, logrando que las interacciones sean más flexibles, transformando lo significativo en estructuras frágiles. Un escenario donde la crisis económica mundial ha modificado inexorablemente el juicio de los ciudadanos sobre la gestión política de las políticas públicas de Estado y ha puesto a prueba la solidez y la
\end{abstract} consistencia de las instituciones. En este contexto, el presente trabajo pretende poner en valor la gestión de la reputación y la transparencia, como herramientas con un enorme valor intangible para los poderes públicos elegidos democráticamente. Con este fin, el objetivo principal de esta investigación es realizar un análisis transversal, -sociológico y estadístico-, de la gestión de los riesgos reputacionales por los principales agentes implicados -públicos y privados-, con conocimiento y colaboración de las áreas directamente afectadas, proponiendo que cada riesgo, también en su dimensión reputacional, tenga un 'propietario' que lo vigile y vele por su prevención. En especial aquellos vinculados con la ética política, el gobierno corporativo, la relación con la sociedad, la comunicación y, por ende, su impacto directo en la "modernidad líquida" actual.

\section{Cómo citar este texto:}

Ana Tomás López (2017): “Transparencia y riesgo reputacional en las políticas públicas de Estado”, en Miguel Hernández Communication Journal, nº, pp. 369 a 411. Universidad Miguel Hernández, UMH (Elche-Alicante). Recuperado el _ de de: Џink del artículo en mhjournal.org] 


\title{
Transparency and reputational risk in the public policies of State
}

\author{
Dra. Ana Tomás López| ana.tomas@protocoloimep.com \\ Instituto Mediterráneo de Estudios de Protocolo
}

\section{Keywords}

Liquid modernity; Public policy; Reputational risk; Transparency; Corruption.

\section{Summary}

1. Introduction. 2. Objectives. 3. Methodology. 4. Results of the analysis, in the framework of Bauman's "liquid modernity". 4.1. About public politicy of State in Spain. 4.2. About perception of corruption and political activity. 4.3. About reputational risk management. 5 . Discussion concerning some proposals for change. 6 . Conclusions. 7. Bibliography 8 . Notes

\section{Abstract}

The metaphor of liquidity proposed by Bauman is the reflection of an increasingly globalized society, where the industrial production regime has impregnated everything, making more flexible interactions, transforming the significant into fragile structures. A scenario where the global economic crisis has inexorably changed the opinion of citizens about the political management of the public policies of State and has tested the strength and consistency of institutions. In this context, this paper aims to highlight the reputation management and transparency, as tools with a huge intangible value for democratically elected Governments. To this end, the main objective of this research is to make a cross sectional study, sociological and statistical-, of the management of reputational risks by the main stakeholders involved -public and private- with knowledge and collaboration of the areas directly affected, proposing that each risk, also in its reputational dimension, has an 'owner' who monitor and ensure its prevention. Especially those linked with political ethics, corporate governance, the relationship with society, communications and, therefore, its direct impact on the current "liquid modernity".

\section{How to cite this text:}

Ana Tomás López (2017): “Transparency and reputational risk in the public policies of State", en Miguel Hernández Communication Journal, nº, pp. 369 to 411. Universidad Miguel Hernández, UMH (Elche-Alicante). Accessed 20 _ in: [paper link in mhjournal.org] 


\section{Introducción}

La obra del insigne sociólogo Zygmunt Bauman se despliega ante nuestros ojos como una extraordinaria oportunidad para diseñar un lienzo en el que trazar los inciertos y desdibujados contornos de nuestro actual Estado Social y Democrático de Derecho. Un modelo de Estado caracterizado por su "liquidez", que expande sus principales atributos y efectos jurídicos, políticos, sociales y económicos a través de un conjunto de políticas públicas cada vez más cuestionadas por la sociedad civil y política (Lahera, 2008), por encontrarse inmersas en lo que Bauman calificó como "Modernidad Líquida"1 (2007b: 7).

En Liquid Times: Living in an Age of Uncertainty (2007b), el autor pretende adentrarse en los atributos de la sociedad capitalista que han permanecido inalterables en el tiempo, junto a aquellos que ya han sido transformados. De esta forma, como apunta Vásquez Rocca (2008), busca "expandir los trazos que eran levemente visibles en las etapas tempranas de acumulación, pero que se vuelven centrales en la fase tardía de la modernidad".

Una de esas características es el fenómeno del creciente proceso de individualización social (Bauman, 2001). Y, frente a este, las alternativas posibles para recrear el espíritu y el accionar comunitario en una era en que las relaciones sociales se han vuelto profundamente precarias, transitorias y volátiles (Bauman, 2004: 171), y cuyo reflejo encontramos en las políticas públicas implementadas en la actualidad que, por otro lado, están siendo seriamente cuestionadas. Estas impactan directamente no solo en la calidad de vida de la ciudadanía, sino también en los propios cimientos del Estado de Bienestar.

Dicha modernidad, caracterizada como un "tiempo líquido", da cuenta del tránsito de una modernidad "sólida", estable y repetitiva, a una líquida, flexible y voluble, en la que las instituciones y estructuras sociales y políticas ya no perduran el tiempo necesario para solidificarse, ni sirven de marco de referencia para la ciudadanía (Bauman, 2005: 126). Porque, en opinión de Bauman, "democracy is already a fiction because the idea of democracy was based on the idea of national sovereignty" (Ordóñez y Sanz, 2013: 176)².

Sloterdijk (2005) profundiza en la misma línea argumentativa para cerrar su trilogía Esferas, al pretender dar cuenta del carácter multifocal de la vida moderna, de los movimientos de expansión de la propia ciudadanía, que "se 
trasladan y aglomeran hasta formar espumas donde se establecer complejas y frágiles interrelaciones carentes del centro y en constante movilidad expansiva o decreciente"3.

Tras la misma, queda el sentimiento dominante de incertidumbre y vulnerabilidad provocado por la "sociedad del riesgo" (Beck, 1998), en parte por el debilitamiento de los sistemas de seguridad que protegían al individuo; así como la renuncia al pensamiento y a la planificación en el largo plazo. En opinión de Bauman, el ciudadano se convierte en un "adicto a la seguridad pero siempre inseguro de ella" (Bauman, 2003: 7-10). Hasta tal punto que la aceptan como si fuera algo lógico o, al menos, inevitable, llegando a contribuir en la normalización del estado de emergencia.

Ahora, al margen de su condición social, sexo o edad, el individuo se sentirá atrapado por sus miedos tanto personales como globales, derivando incluso en el miedo al miedo (Bauman, 2007a). Los temores son muchos y variados, reales o imaginarios: un ataque terrorista, el desempleo, las enfermedades, el hambre o los desastres medioambientales, entre muchos otros.

Por tanto, serán el Estado, los Gobiernos y sus representantes políticos los encargados de remontar y transformar dicha precariedad e inestabilidad asociada a la desaparición de patrones a los que anclar certezas y resultados tangibles para la sociedad en su conjunto (Bauman, 1999). Por su parte, también requerirá de una mayor flexibilidad de la ciudadanía y disponibilidad para cambiar las tácticas obsoletas a la hora de abandonar compromisos y lealtades (Bauman, 2011). Un fenómeno con un claro reflejo en la actual desafección y apatía política de la sociedad civil en pleno siglo XXI.

A través de estos postulados, Bauman pretende evidenciar la fragilidad de los vínculos humanos (Borghi, 2007), motivado por la presencia de la esfera comercial, que ahora lo impregna todo (2007b). Hasta tal punto que las relaciones se miden en términos de costo y beneficio (Bauman \& Tester, 2001: 115).

En resumen, esta nueva etapa "líquida" constituye una referencia de la finalización de una fase de "incrustación" de la ciudadanía en estructuras "sólidas", como las instituciones democráticas o el régimen de producción industrial, con un fuerte raigambre territorial (Vásquez Rocca, 2008). Sobre esta base, el autor defiende la desnaturalización del fenómeno de la apropiación del territorio, que pasa de ser un recurso a un lastre, motivado por los efectos adversos sobre los dominadores, al obligarlos a las engorrosas e 
inacabables responsabilidades que inevitablemente supone la administración de un territorio.

Como resultado, los modelos y estructuras sociales y políticos ya no perduran lo suficiente como para enraizarse y gobernar las costumbres de los ciudadanos. De forma sutil y paulatina, se han ido sucediendo transformaciones y pérdidas como la separación del poder y la política en un mundo en el que el verdadero Estado es el dinero, junto a la renuncia de la memoria; pues "el olvido se presenta como condición del éxito" (Bauman, 2003: 58-59).

Así pues, en el presente trabajo tratamos de desentrañar las claves centrales del pensamiento de Bauman, en torno a su concepto de "modernidad líquida", el cual nos da pábulo a establecer un marco de referencia común y contrastado con la actualidad política en España y en Europa en el tema que nos ocupa: el análisis de las políticas públicas de Estado. La finalidad es poder discernir si sus teorías siguen estando vigentes hoy en día y si pueden ser aplicadas en términos absolutos, o bien cabe añadir algunos matices, tras rendirnos ante la objetividad de los datos que arroja la investigación sociológica y politológica desarrollada.

Sobre esta base, encontramos amplias contribuciones relativas al estudio de la transparencia y la reputación corporativa en el ámbito científico y académico. No obstante, el tema del liderazgo y la gestión del riesgo reputacional en el marco de las políticas públicas todavía continúa siendo un escenario virgen, susceptible de ser explorado en mayor profundidad. De ahí se deriva la importancia y la justificación de realizar esta investigación sobre una tendencia en auge en el ámbito de los sistemas y los partidos políticos actuales: la generación de un liderazgo político basado en valores, que contribuyan a reformar la base de nuestra democracia actual en España y en el continente europeo.

Con este fin, nos apoyamos en las teorías del sociólogo, filósofo y ensayista polaco, Zygmunt Bauman, para centrar nuestro trabajo y analizar temas tan relevantes como son la transparencia y la gestión del riesgo reputacional, en el marco de las políticas públicas de Estado en España. Tema de debate sobre el que gira este monográfico en torno a la gestión de la influencia y la reputación en las sociedades postmodernas / líquidas.

Para finalizar, es oportuno adelantar que nuestro análisis no trazará unos contornos tan pesimistas como aquellos sobre los que el autor asienta los pilares de su pensamiento. Por ello, si bien la tesis que tratamos de defender 
no es, -en cierto modo- tan "sombría", nos ayuda a comprender fenómenos actuales como la desafección política o la necesidad de evolución y transformación del marco de actuación de las políticas públicas desarrolladas por el actual Estado de Derecho y del Bienestar ${ }^{4}$ de las sociedades modernas contemporáneas, ajustándose a las nuevas necesidades y expectativas de la ciudadanía en el siglo XXI.

\section{Objetivos}

En este sentido, el objetivo principal de esta investigación es analizar si existe una gestión eficiente de la transparencia y la gestión del riesgo reputacional en el marco de las políticas públicas de Estado en España y si estas encuentran acomodo y significación en el marco de esta "modernidad líquida" plasmada por Bauman. Comprender, en segundo lugar, si continúan estando vigentes, al hilo de los resultados que arrojan las principales encuestas de investigación sociológica en España (principalmente, las del Centro de Investigaciones Sociológicas) y si, además, son capaces de ponderar los posibles riesgos, explicando y tratando de encontrar respuestas y soluciones -generales y específicas, individuales y colectivas- a los problemas que actualmente emergen sobre la transparencia y los riesgos reputacionales que están poniendo en peligro $-\mathrm{O}$ al menos cuestionando- los pilares del Estado moderno. Entre ellos, la corrupción o la desafección política.

Con esta finalidad, y al igual que Bauman, no pretendemos construir teorías o sistemas definitivos. Nuestro objetivo es más bien pragmático. Tratamos de ofrecer un marco crítico y contrastado para las Ciencias Sociales, un espacio de reflexión sobre el que poder describir y denunciar las contradicciones de nuestro actual modelo de Estado, en el que la transparencia, la adecuada gestión del liderazgo y la minoración del riesgo reputacional se convierten en ejes centrales para la adecuada gestión de las políticas públicas diseñadas por los distintos gobiernos en cada uno de sus niveles territoriales.

Siguiendo esta línea argumentativa, extraeremos una serie de conclusiones, derivadas de los resultados obtenidos a través de la presente investigación y que supondrán una síntesis contrastada entre el modelo desarrollado por Bauman y la realidad que arrojan las cifras y variables estadísticas, de forma clara y sintética.

Nuestra pretensión es elaborar recomendaciones plausibles para la teoría y la práctica profesional de la Sociología, las Ciencias Políticas y otras disciplinas científicas afines. Al mismo tiempo que posibles sugerencias que puedan 
inspirar futuras líneas de investigación en torno a la transparencia y la gestión del riesgo reputacional en las políticas públicas que se han venido desarrollando en España y en el marco de la Unión Europea.

\section{Metodología}

Para responder a los objetivos planteados, emplearemos una metodología sociológica e histórica. Con este fin, partiremos del estudio y análisis doctrinal de los trabajos desarrollados por Bauman en torno al contexto de las sociedades postmodernas / líquidas.

Para llevar a cabo la investigación sociológica, realizaremos un análisis cualitativo y cuantitativo, evaluando la situación política y económica actual y su evolución futura, la labor del gobierno de la nación y de los principales partidos de la oposición, la intención y la estimación de voto en elecciones generales, y la auto ubicación ideológica en una escala de graduación, a través del análisis detallado de los barómetros del CIS más recientes.

A este respecto, la metodología utilizada por el CIS para la construcción de sus indicadores de temas sociales más conocidos se apoya en dos instrumentos fundamentales ${ }^{5}$. En primer lugar: los números índices ${ }^{6}$. En segundo lugar: las encuestas de opinión 7 .

Con este fin, podemos agrupar por temas los índices e indicadores que se elaboran a partir de los barómetros. Y tal y como sigue, según se establece en la propia metodología utilizada por el CIS ${ }^{8}$ :

- Indicadores de la situación económica?

- Indicadores de la situación política ${ }^{10}$.

- Indicadores del sistema político ${ }^{11}$.

Posteriormente, se elaboran los siguientes indicadores:

- Indicador de la Labor del Gobierno (ILG) ${ }^{12}$.

- Indicador de la Labor de la Oposición (ILO $)^{13}$.

- Indicadores electorales ${ }^{14}$.

- Auto-ubicación ideológica, como variable de tipo cuantitativo ${ }^{15}$. 


\section{Resultados del análisis, en el marco de la sociedad "líquida" de Bauman}

\subsection{De las políticas públicas de Estado en España}

Como hemos tenido oportunidad de evidenciar, el sociólogo Zygmunt Bauman introdujo el concepto de "Modernidad líquida" como puente para definir el estado fluido y volátil de la sociedad actual, con valores escasamente sólidos, donde la incertidumbre por la vertiginosa rapidez de los cambios ha debilitado los vínculos humanos, -y en especial los políticos-. Lo que antes podían ser considerados unos nexos poderosos en ambos contextos (político y social), ahora se han convertido en lazos provisionales y frágiles para la sociedad.

Esta fase líquida y contradictora inunda indefectiblemente también al contexto socio-político, a tenor del retrato que ofrecen las numerosas encuestas que se publican en el marco de las investigaciones sociológicas ${ }^{16}$, y que muestran una sociedad del bienestar en la que la dialéctica izquierda-derecha ha ido perdiendo intensidad progresivamente, pese a conservar un fuerte sentimiento nacionalista; pero que, al mismo tiempo, está mutando su piel, su actitud y la forma que tiene la ciudadanía de vivirlo a lo largo de estas dos últimas décadas, como podemos apreciar en el siguiente gráfico que muestra la tasa interanual de la auto ubicación ideológica media, entre 1996 y 2017.

\section{Gráfico 1. Fuente: Tasa interanual de la auto ubicación ideológica media, entre 1996 y 2017, CIS. ${ }^{17}$}

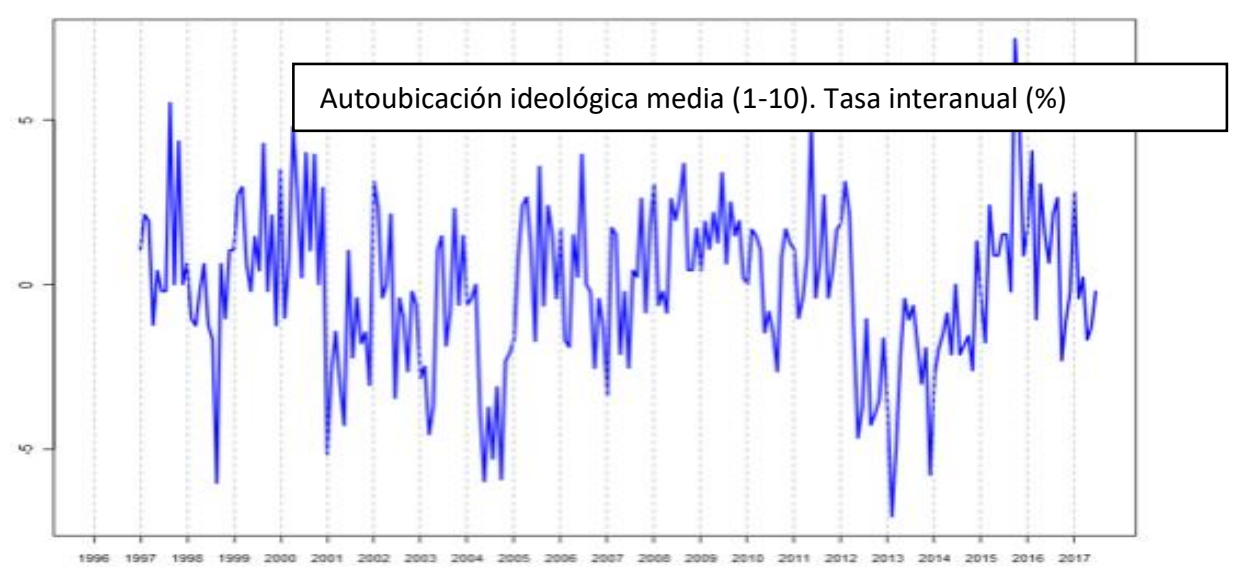


Este hecho se pone asimismo de manifiesto en la última encuesta del Centro de Investigaciones Sociológicas (en adelante CIS), en su último Avance de Resultados de Marzo de 2017, que sitúa al votante español en un espectro ideológico de centro-moderado, cuando se le pregunta en qué casilla de izquierda a derecha se ubica ideológicamente. Por lo que vemos claramente en este gráfico cómo pierden fuerza en el momento actual aquellas posiciones que se situaban en los extremos más antagónicos.

Gráfico 2. Fuente: Elaboración propia, a partir del Avance de Resultados del Barómetro del CIS, de Marzo de $2017^{18}$

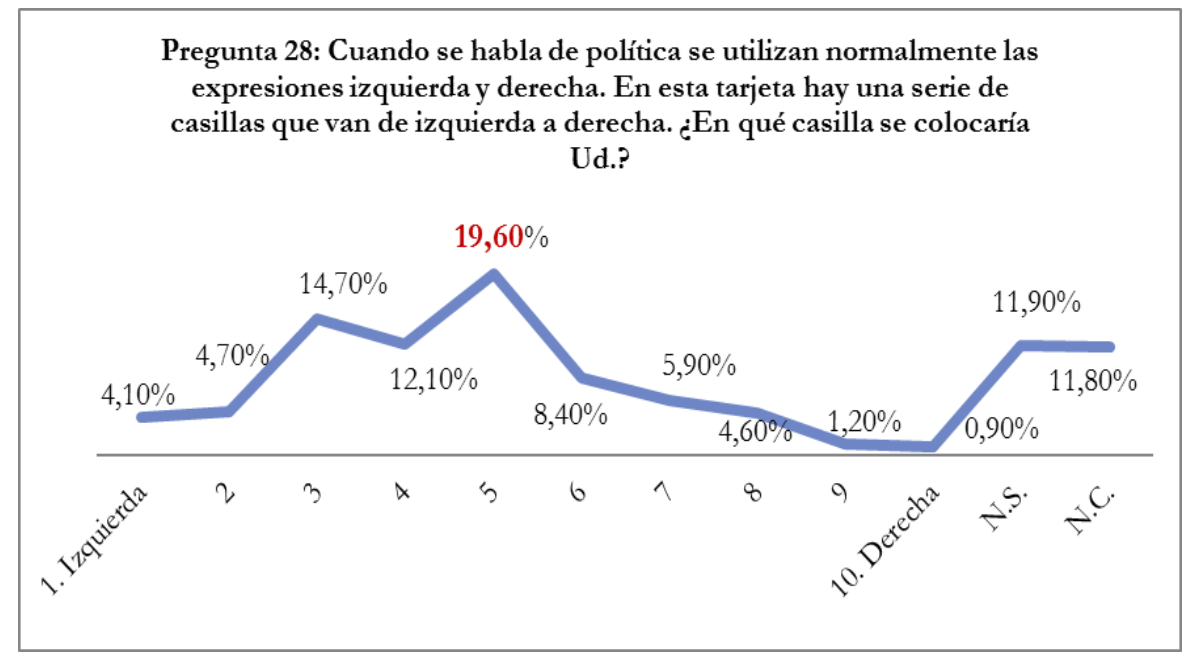

Coincidiendo con la tesis de Villoria (2015: 1), este fenómeno ha estado motivado por una creciente desafección política, generada por la desconfianza hacia las instituciones representativas, hacia los políticos, los partidos y las instituciones del Estado de Derecho, desde el comienzo de la crisis económica. Un hecho probado en la literatura reciente sobre este fenómeno, que refleja el crecimiento de la presión a favor de la desconfianza institucional, sobre una base dual; por un lado, la de una crisis económica que ha disparado las cifras del desempleo y los recortes sociales, promoviendo más desigualdad; por otra, la de la sensación popular de que el sistema no ha respondido en igual medida y con cercanía a las demandas y necesidades ciudadanas, en un momento especialmente difícil (Torcal, 2014).

Así se refleja en diversos estudios internacionales, en los que se destaca la importancia del déficit de "responsividad"19 en la explicación de la desafección 
(Bellucci et al., 2012; Pharr \& Putnam, 2000; Norris, 1999). También a nivel nacional, en los datos que se recogen en este último Barómetro del CIS. A la pregunta: "¿cuál es, a su juicio, el principal problema que existe actualmente en España? ¿Y el segundo? ¿Y el tercero?”. Los encuestados, formados por una muestra de población de 2.487 personas, sostienen que es el paro el problema más grave al que España ha de hacer frente en el momento actual (tesis que sostiene un 46,7\% del total), seguido de la corrupción y el fraude (un 18,9\%) y los/as políticos/as en general, los partidos y la política (con un 8,2\%).

A continuación, los/as españoles/as también dicen estar preocupados (aunque en menor medida) por los problemas de índole económica y social, así como por el Gobierno y partidos o políticos/as concretos/as. Estas respuestas son claramente sintomáticas de la desmovilización social y la desafección política imperante en la ciudadanía española actual.

\section{Gráfico 3. Fuente: Elaboración propia, a partir del Avance de Resultados del Barómetro del CIS, de Marzo de $2017^{20}$}

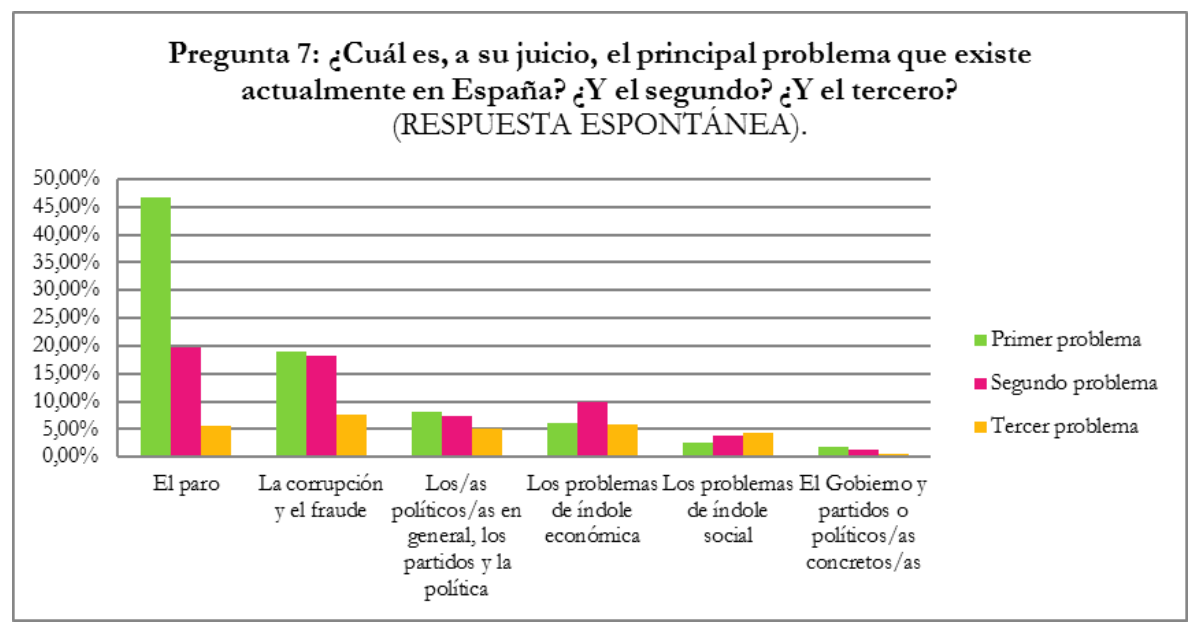

De esta forma, la emergencia de multitud de escándalos de corrupción y la consiguiente preocupación por este fenómeno, medida esencialmente a través de estas encuestas de percepción, también ha ejercido una presión haciendo crecer la desconfianza de la ciudadanía desde los inicios de la crisis. Esta ha afectado no sólo a las instituciones representativas, sino también a la confianza social y a las instituciones propias del Estado de derecho (Villoria et al., 2013; De Lancer y Villoria, 2014), con el correspondiente deterioro de la cultura de la legalidad y el acrecentamiento de los problemas de acción colectiva (Villoria y Jiménez, 2014; Villoria et al., 2014) ${ }^{21}$. 
Así podemos constatarlo en el gráfico número 4, donde se muestra el porcentaje de votos obtenidos por las siete formaciones políticas más votadas en las elecciones generales del 26 de junio de 2016. El mismo constituye la radiografía contemporánea de la ruptura progresiva del bipartidismo imperante desde la puesta en marcha de la actual democracia en España.

Gráfico 4. Fuente: Elaboración propia, a partir de los resultados de las elecciones al Congreso de los Diputados y al Senado, celebradas el 26 de junio de $2016^{22}$

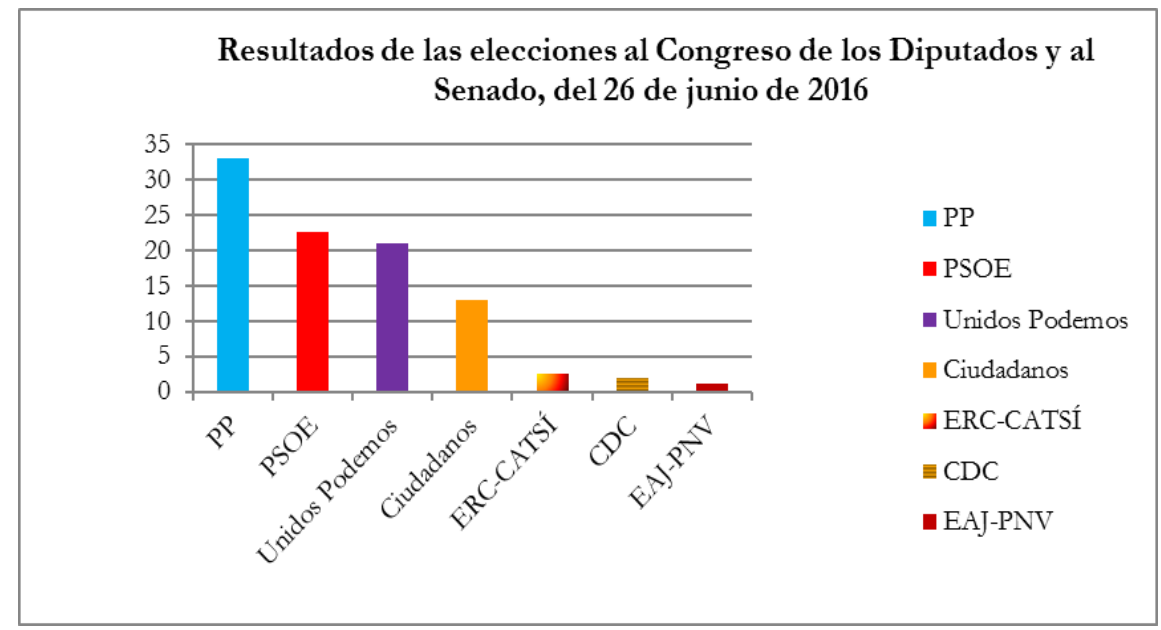

A nivel histórico, este hecho especialmente evidenciable si atenemos el siguiente gráfico del CIS, que muestra la evolución de la estimación de voto en elecciones generales a los partidos políticos más votados (PP, PSOE, Podemos y C’s), entre los años 1996 y 2017. 
Gráfico 5. Estimación de voto en las elecciones generales, celebradas entre 1998 y 2017 Fuente: Serie de la estimación de voto en elecciones generales -PP/PSOE/Podemos/C's, CIS, entre 1996 y $2017^{23}$

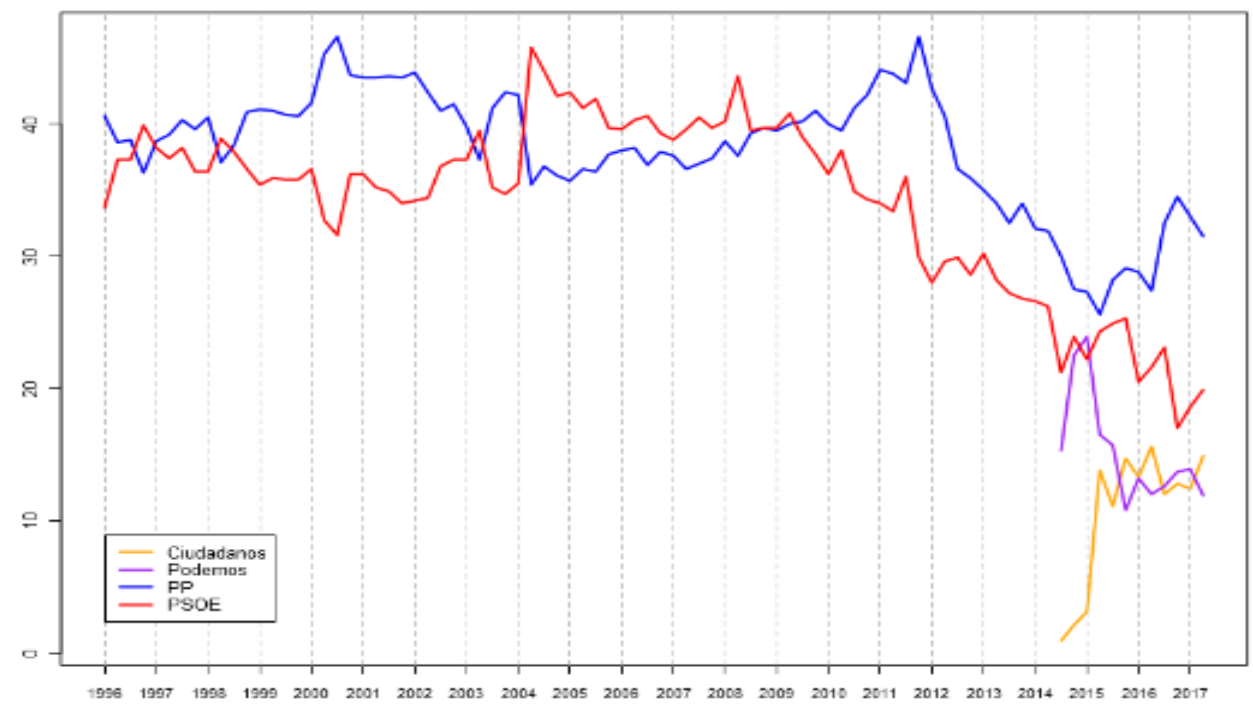

Sin embargo, pese a lo que podría esperarse en el marco de esta "modernidad líquida", en unos tiempos en los que se han desarrollado profundos sentimientos soberanistas, al mismo tiempo que determinadas gestiones sobre políticas públicas han desacreditado la existencia de los Gobiernos autonómicos, el modelo de Estado existente mantiene su solidez entre los españoles. La mayoría no quiere cambios, según constata el estudio de enero de 2017 del CIS.

Ante la pregunta: “¿con qué fórmulas alternativas de organización territorial de Estado en España está usted más de acuerdo?”, una mayoría del 38,2\% de los encuestados (de un total de 2.487) respondieron que prefieren un Estado con Comunidades Autónomas como en la actualidad, frente a las opciones de recortar o incrementar su grado de autonomía. El 18,7\%, por el contrario, preferiría un Estado con un único Gobierno central sin autonomías. Sin llegar a una posición tan concluyente, a un 10,3\% le gustaría un Estado en el que las comunidades tuvieran menor autonomía.

En la otra orilla, el 14\% preferiría un Estado en el que las comunidades tuvieran mayor autonomía que ahora. Y el 8,9\% desearía un Estado en el que 
se reconociera a las comunidades la posibilidad de convertirse en Estados independientes.

\section{Gráfico 6. Fuente: Elaboración propia, a partir del Barómetro del CIS, de Enero de $2017^{24}$}

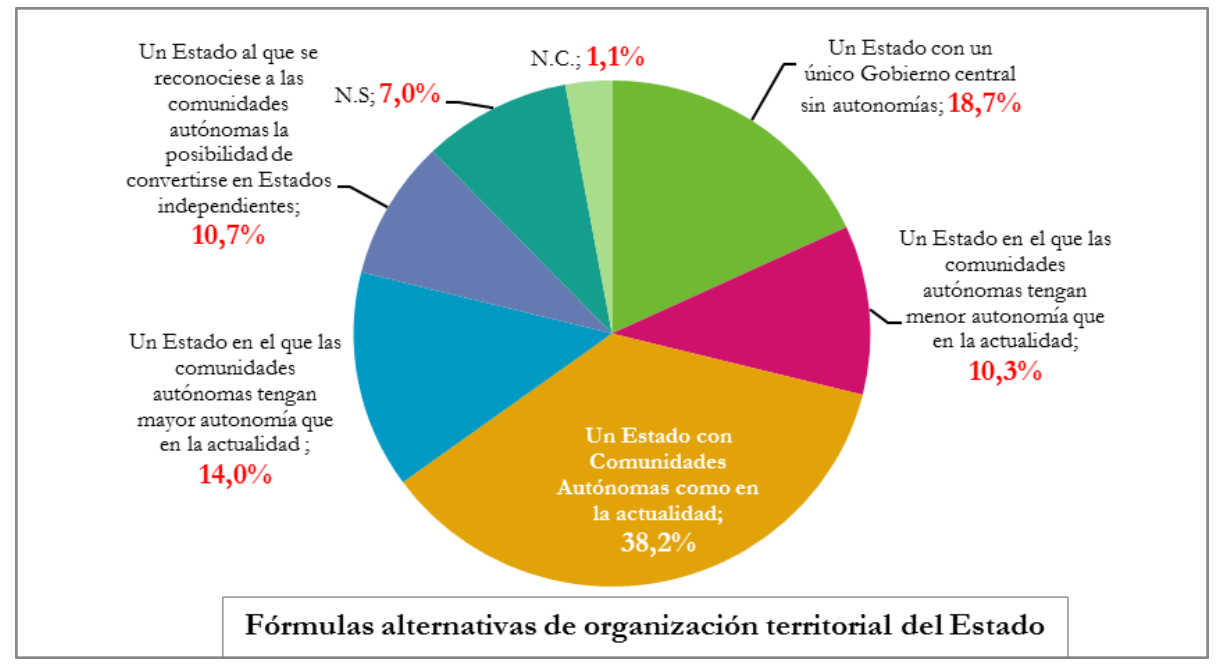

Por ideologías, la fórmula de mantener la actual estructura del Estado es la mayoritaria (recordemos: el 38,2\% del total) es la preferida de aquellos que en las elecciones generales de 2016 optaron por votar al PSOE (52,5\%). También lo es para los votantes del PP (41\%), seguidos de los C's $(33,9 \%)$ y de Unidos Podemos (30,33\%).

Les siguen aquellos que se decantan por un Estado con un único Gobierno central sin autonomías (con un 18,7\% del total). Entre ellos, es la opción mayoritaria para los del PP $(31,1 \%)$ y C,s $(29,9 \%)$.

A continuación, en torno a los que defienden una fórmula de Estado en el que las Comunidades Autónomas tengan mayor autonomía que en la actualidad (un 14\% del total), se sitúan a la cabeza los de Compromís-Podemos-EUPV (43,4\%), junto a los de En Comú Podem (40\%) y En Marea y EAJ-PNV (con un $33,3 \%$, cada uno de ellos).

Muy de cerca, un 10,7\% del total de votantes se decanta por un Estado en el que se reconozca a las Comunidades Autónomas la posibilidad de convertirse en Estados independientes. En especial entre los de ERC (88,5\%), CDC $(86,7 \%)$ y los de EAJ-PNN (47,6\%). 


\subsection{De la percepción de la corrupción y la actividad política}

De forma paralela, la transparencia es considerada actualmente un instrumento de medición y control del grado de madurez y realización del Estado democrático y de Derecho. En el ámbito comunitario, la transparencia y el derecho de acceso a la función pública se encuentran reconocidos como principios de Derecho Administrativo en la mayoría de sus Estados miembros. Los cuales se han ido consolidando paulatinamente como instrumentos de control y prevención de la corrupción de los gobiernos y las instituciones públicas al servicio de la ciudadanía.

De esta forma, lo que hace unos años era considerada una "enfermedad puntual" para hacer frente de forma heterodoxa a la financiación de los partidos políticos con capacidad para gobernar, ha mutado en una especie de metástasis necesitada de un tratamiento de choque -jurídico, jurisprudencial y político- para salvar la politeya española y europea.

No en vano, la corrupción política es un asunto que inquieta de forma notable a la ciudadanía española y europea. Desde 2014, según los barómetros del CIS, en torno al $50 \%$ de encuestados la situaban entre sus tres mayores preocupaciones, solo superada por el paro. Adicionalmente, un 15\% manifestaba que era el problema español que más les afectaba personalmente. También los países septentrionales y anglosajones poseen una larga trayectoria de corruptelas descrita por la academia y los mass media de los países implicados, conocido en la jerga estadounidense como pork barrel o barril porcino (Moreno, 2017).

Así pues, como hemos tenido oportunidad de avanzar en el epígrafe anterior (ver gráfico número 2), según los datos del barómetro del CIS, del avance del mes de marzo, la corrupción ocupa el segundo lugar en la lista de los problemas más acuciantes en España, detrás del paro. En concreto, cuando se pregunta a los encuestados, estos responden que el paro es preocupante para un $18,90 \%$ (en primer lugar), para un $18,20 \%$ (en segundo lugar) y para un $7,60 \%$ (en tercer lugar). Si bien, no lo es tanto como el desempleo, que preocupa a casi a la mitad de los encuestados (exactamente, un 46,7\%), ocupando la primera posición. 
Gráfico 7. Fuente: Elaboración propia, a partir del Avance de Resultados del Barómetro del CIS, de Marzo de $2017^{25}$

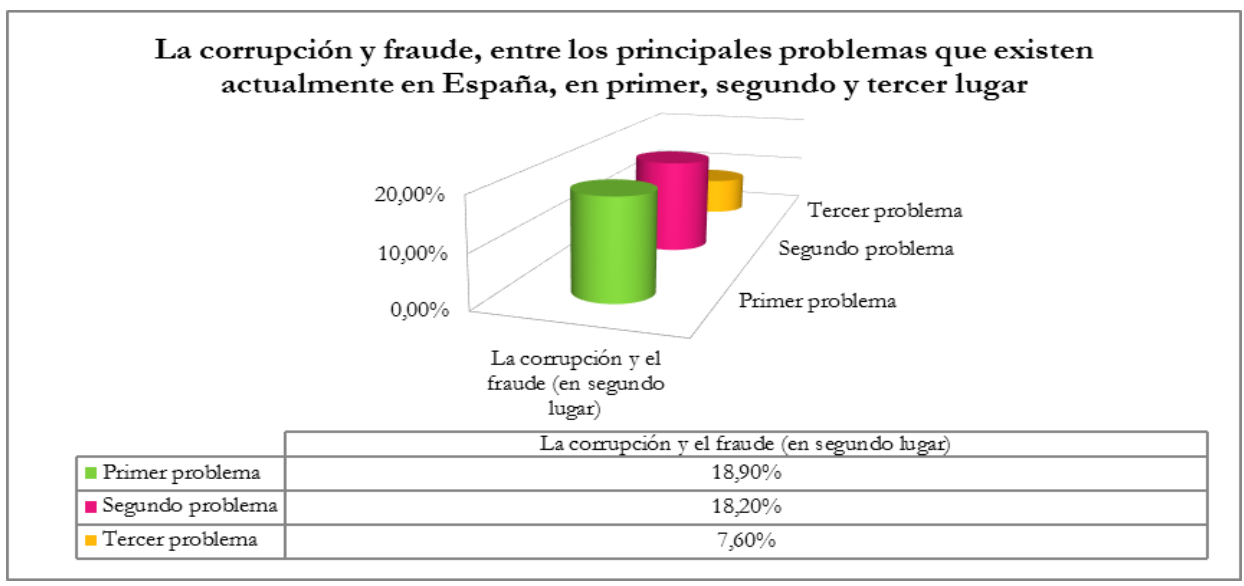

Si tenemos en cuenta la evolución de este sentimiento y/o percepción de preocupación de los españoles en torno al problema de la corrupción y el fraude, vemos que esta se ha mantenido constante en el tiempo, como segundo problema más apremiante para España. Para su análisis, hemos tomado como referencia el período comprendido entre enero de 2016 hasta la fecha actual, en el que hemos considerado también el avance del barómetro del CIS del mes de marzo de 2017.

En el siguiente gráfico podemos contemplar la evolución de la percepción de los encuestados sobre este problema. 


\section{Gráfico 8. Fuente: Elaboración propia, a partir del Avance de Resultados del Barómetro del CIS, de Marzo de $2017^{26}$}

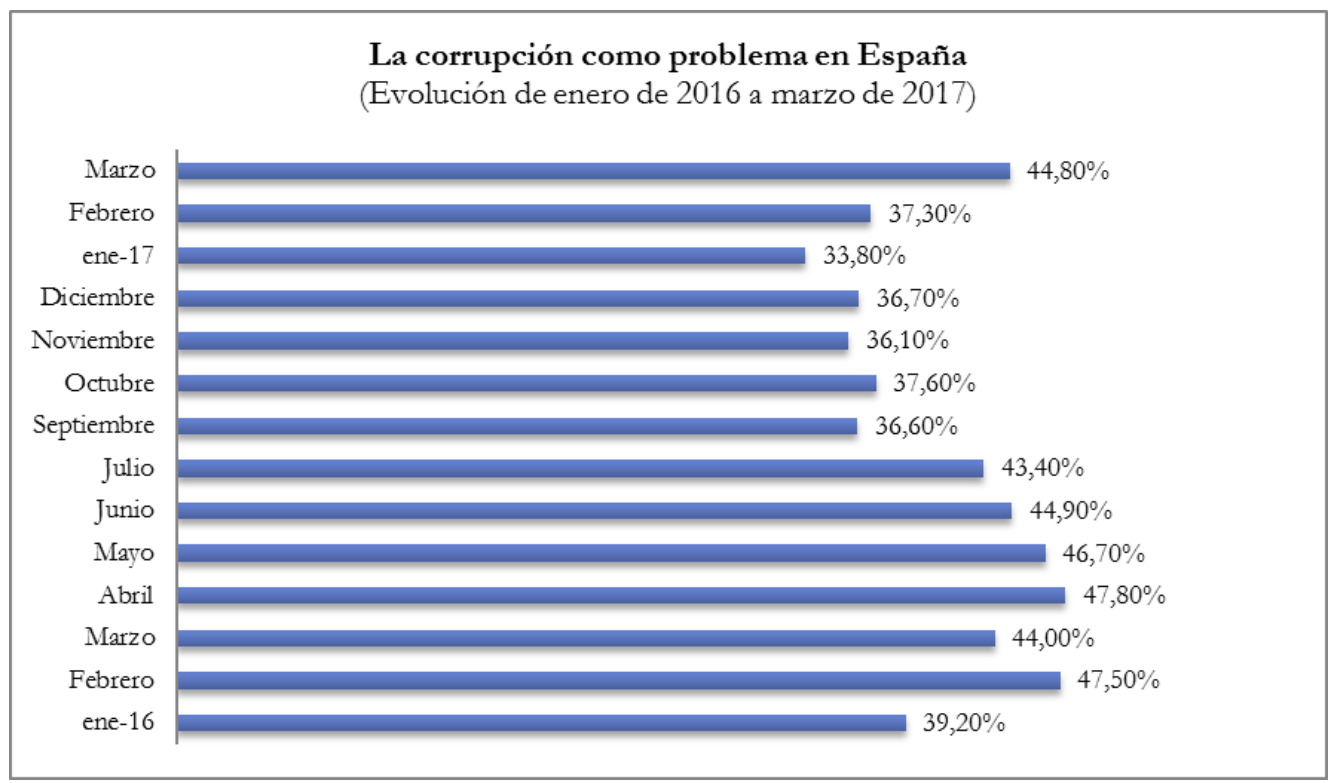

En él podemos evidenciar cómo (en esta serie temporal) dicho porcentaje alcanza una media del $41,17 \%$ de los encuestados. Por meses, además esta ha ido variando, hasta llegar a alcanzar la cifra más baja en enero de 2017(con un porcentaje de un 33,80\%) y la más alta, en el mes de abril de 2016 (con un $47,8 \%$ ). Es significativo, asimismo, el incremento de esta percepción negativa a partir del mes de febrero de 2017. Ello es fruto, sin duda, de los nuevos casos de corrupción que se han venido destapando a la opinión pública, relacionados con el supuesto desvío de fondos en la empresa pública del Canal de Isabel II, la detención del ex presidente madrileño Ignacio González, junto a otros casos de corrupción relacionados con la operación Lezo, la trama Púnica, la Gürtel, Taula, o el caso Noos, entre otros.

Así pues, y coincidiendo con la tesis de Aguilera (2014), la corrupción constituye el mayor obstáculo para el desarrollo económico y social de un país. Según el Banco Mundial, su ejercicio no solo menoscaba los recursos que el Estado utiliza para satisfacer las necesidades de sus ciudadanos, también desincentiva la realización de inversiones, frena el desarrollo económico, 
perpetúa los niveles de pobreza y promueve la ineficiencia y la inestabilidad (Campos y Praghan, 2009) ${ }^{27}$.

Por otro lado, en base a los últimos datos publicados por la ONG Transparencia Internacional (TI), relativos a 2016, España se sitúa en el puesto 41 de los 176 países integrantes del índice de percepción de la corrupción, con una nota de 58, al igual que Georgia y Costa Rica. Su peor clasificación de la historia. También llama la atención la posición que nuestro país ocupa entre los 28 Estados integrantes de la Unión Europea, situándose en el puesto 17.

Otro dato que invita a la reflexión es la evolución que ha tenido España en dicho ranking durante los últimos cinco años; pues, desde 2012, la percepción de la corrupción en España ha crecido exponencialmente, pasando del puesto 30 en 2012 al 41 en la actualidad ${ }^{28}$.

Siguiendo esta línea argumentativa, en la siguiente imagen podemos ver estos datos reflejados gráficamente en el "Mapa Mundial de la Corrupción", basándose en los Índices de Percepción de la Corrupción (IPC) de 2016.

\section{Imagen 1. Fuente: Transparency International España. Mapa Mundial de la Corrupción (IPC 2016) ${ }^{29}$}

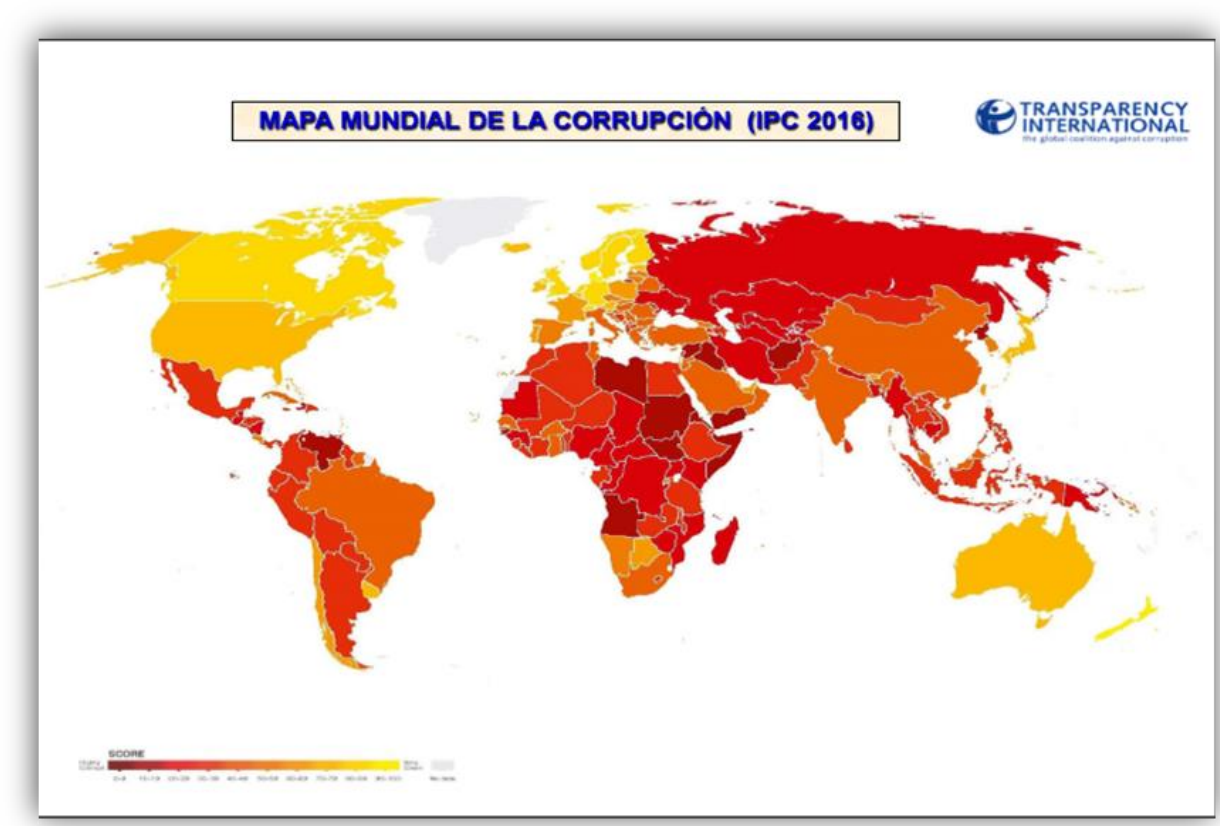


Como respuesta, en la práctica totalidad de los países de Europa se han aprobado leyes de transparencia y de acceso a la información pública. El conjunto de normas nacionales, sumadas a las adoptadas en el seno de la Unión Europea y del Consejo de Europa, configuran un extenso corpus iuris sobre transparencia y acceso a la información pública en el Viejo continente. Sin embargo, la frontera entre lo que debe estar permitido en el acceso al poder público y aquello que da lugar a actividad sospechosa, es lo que hace de la transparencia materia pendiente en la democracia española.

En España, la tramitación de la Ley 19/2013, de 9 de diciembre, de Transparencia, Acceso a la Información Pública y Buen Gobierno por parte de las Cortes Generales reabrió el debate acerca de las influencias que reciben los poderes públicos en la toma de decisiones. Una controvertida cuestión que se inicia en el año 2008, con motivo del "Informe del Consejo de Estado sobre la inserción del Derecho Europeo en el ordenamiento español", que ya advertía que "una cuestión que no plantea de modo frontal la consulta del gobierno, pero que emerge sin remedio al abordar las suscitadas, radica en la intervención que, en el proceso normativo y decisorio comunitario, tienen los grupos representativos de intereses sociales y el diálogo social”.

La corrupción se ha instalado en nuestra sociedad líquida y ha calado todos los cimientos del sistema institucional, desde la Casa Real a la Jefatura del Estado, pasando por los poderes legislativo y judicial, hasta llegar a las Comunidades Autónomas, los sindicatos o el mundo empresarial y el deportivo, saltando a la opinión pública continuamente. ${ }^{30}$

De hecho, según los barómetros del CIS analizados en la presente investigación, en el periodo comprendido entre enero de 2016 y marzo de 2017 (último Avance), vemos que, junto al fraude y la corrupción, a los encuestados también les preocupa significativamente las actuaciones de los políticos en general, de los partidos y la política en general, representando una media de un 23,33\% del total durante todo el periodo de análisis.

Sin embargo, muestran una menor preocupación por las actuaciones del gobierno y/o de representantes políticos concretos, (con una media del 2,87\% del total de encuestados en el periodo considerado). Dato que llama poderosamente la atención, si tenemos en cuenta otros, como es su opinión sobre la situación política de España, que califican de "mala" o "muy mala" 31 , como mostraremos a continuación. 
Gráfico 9. Fuente: Elaboración propia, a partir del Avance de

Resultados del Barómetro del CIS, de Marzo de $2017^{32}$

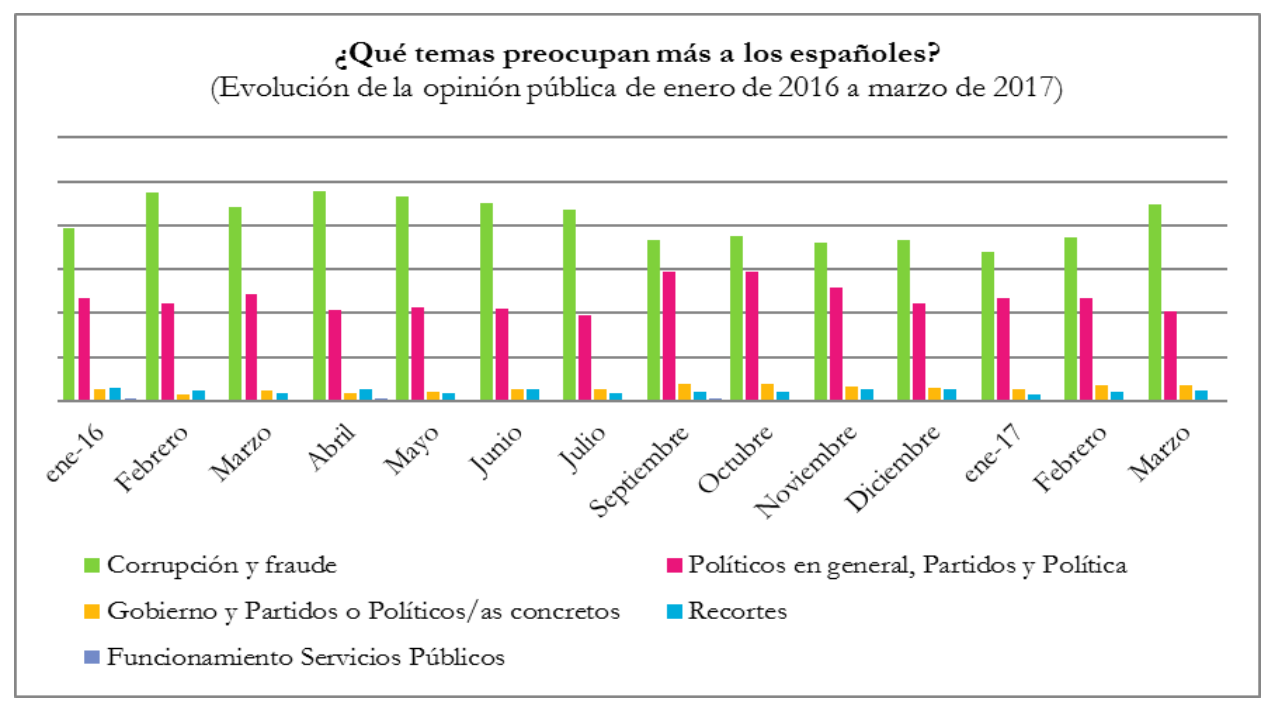

\subsection{De la gestión del riesgo reputacional}

Hasta aquí, los resultados de la investigación constituyen la principal evidencia de que una adecuada gestión del liderazgo ha de empezar a formar parte de la lista de prioridades de los partidos políticos de corte tradicional. Junto a esta, la meta de crear valor democrático y una reputación positiva se sitúa ya en el epicentro no solo del debate, sino de la agenda política. Por lo que la gestión del riesgo reputacional se está convirtiendo en prioridad estratégica para salir de la crisis política e institucional en la que estamos inmersos (Ramió Matas, 2015: 18).

Numerosas organizaciones -públicas y privadas- han entendido que esto solo será posible si son capaces de proyectar una imagen que atraiga perfiles políticos éticos, creíbles y responsables en nuevos escenarios políticos. Perfiles que no solo deben orientarse a la creación de valor para el votante potencial, sino en el conjunto del entorno político, social y económico, y en el largo plazo (Ramírez Alujas, 2011: 12-13). Veamos por qué.

El siguiente gráfico, elaborado por el Centro de Investigaciones Sociológicas, constituye la muestra evidente de que nuestras clases políticas deberían enfocarse prioritariamente hacia una adecuada gestión del liderazgo y la 
reputación política, si quieren garantizar la estabilidad del sistema democrático y recuperar la confianza ciudadana.

En la última década (con el comienzo de la crisis financiera internacional, en especial a partir del año 2008) el indicador relativo a la percepción de la "situación política" del país ha caído en picado, alcanzando las cifras más bajas de toda la década en 2015. También se produce un descenso muy significativo en los indicadores de "confianza política" (que alcanza su mínimo histórico en 2013). Así como en el de "expectativas" (cuyos mínimos también tienen lugar en 2013), si bien este se mantiene más estable que los anteriores.

En este sentido, los partidos políticos (en especial aquellos que tienen responsabilidades de gobierno) deberían aprovechar la mejora de estos indicadores y, por tanto, el repunte de la confianza del electorado a partir del año 2014, con el diseño de nuevas políticas públicas más transparentes y eficientes, centradas en las necesidades y expectativas de la ciudadanía.

\section{Gráfico 10. Fuente: CIS, Gráfico de los indicadores de la situación política en España. Evolución de 1996 a $2017^{33}$}

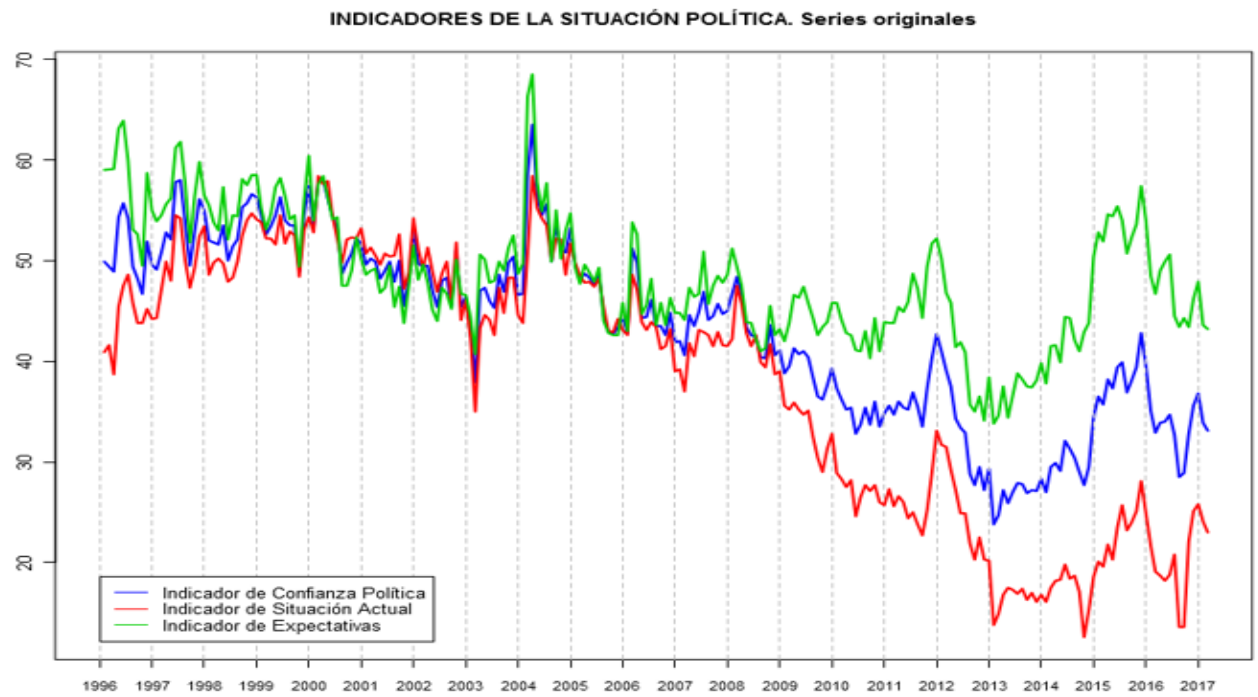

Si nos detenemos a continuación en los datos más recientes, en concreto los de la encuesta del CIS de marzo de 2017, vemos cómo un porcentaje muy elevado de las personas encuestadas (un 93,3\%, del total de una muestra de 2.487) califica la situación política general de España como regular, mala o 
muy mala; situándose incluso el porcentaje más alto (un 36\%) entre los que opinan que la situación es, especialmente, muy mala.

Gráfico 11. Fuente: Elaboración propia, a partir del Avance de Resultados del Barómetro del CIS, de Marzo de $2017^{34}$

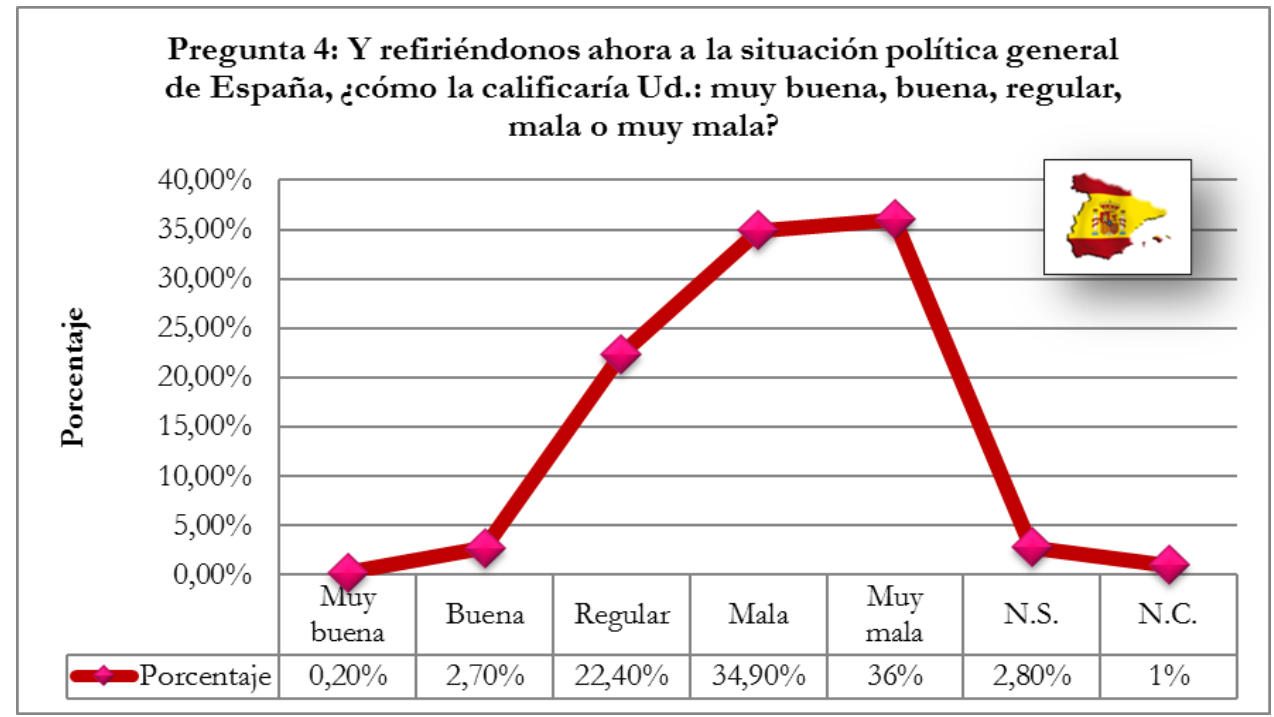

Sobre las perspectivas futuras, en respuesta a las preguntas del CIS: "¿cree usted que la situación política actual del país es mejor, igual o peor que hace un año?", y, "¿cree usted que dentro de un año la situación política del país será mejor, igual o peor que ahora?”, comprobamos que los encuestados siguen manteniendo la misma actitud pesimista. La mayoría opina (respecto a la situación actual, relativa a marzo de 2017) que la situación política es igual que hace un año (un 54,50\%) y mantiene prácticamente la misma opinión respecto a 2018, si bien esta percepción baja casi siete puntos porcentuales (hasta el 47,60\%).

Sobre los datos globales de la estimación pública para el año 2018, podemos evidenciar una mejora de la percepción social respecto a la situación política, aunque se mantengan prácticamente las mismas variables, con ligeras variaciones. Por un lado, observamos esta mejora de la opinión pública de los encuestados, que opina (en un 12,40\%) que la situación política en 2018 será igual que en 2017 (frente al 10,10\%, de 2017), lo cual supone un ascenso del $2,3 \%$ sobre la opinión relativa al año en curso. Por otro lado, también comprobamos que el porcentaje de encuestados que piensan que la situación empeorará en 2018 desciende en -6,7 puntos porcentuales respecto a 2017. 
Por otro lado, llama la atención la subida significativa de indecisos, que contestan que "no saben" si la situación política mejorará en 2018 (un 14,90\%, frente al 3,70\% respecto a 2017). Un claro reflejo de la alta dosis de incertidumbre que circunda a la opinión pública sobre la situación de la política nacional, tal como se refleja en el siguiente gráfico.

\section{Gráfico 12. Fuente: Elaboración propia, a partir del Avance de Resultados del Barómetro del CIS, de Marzo de $2017^{35}$}

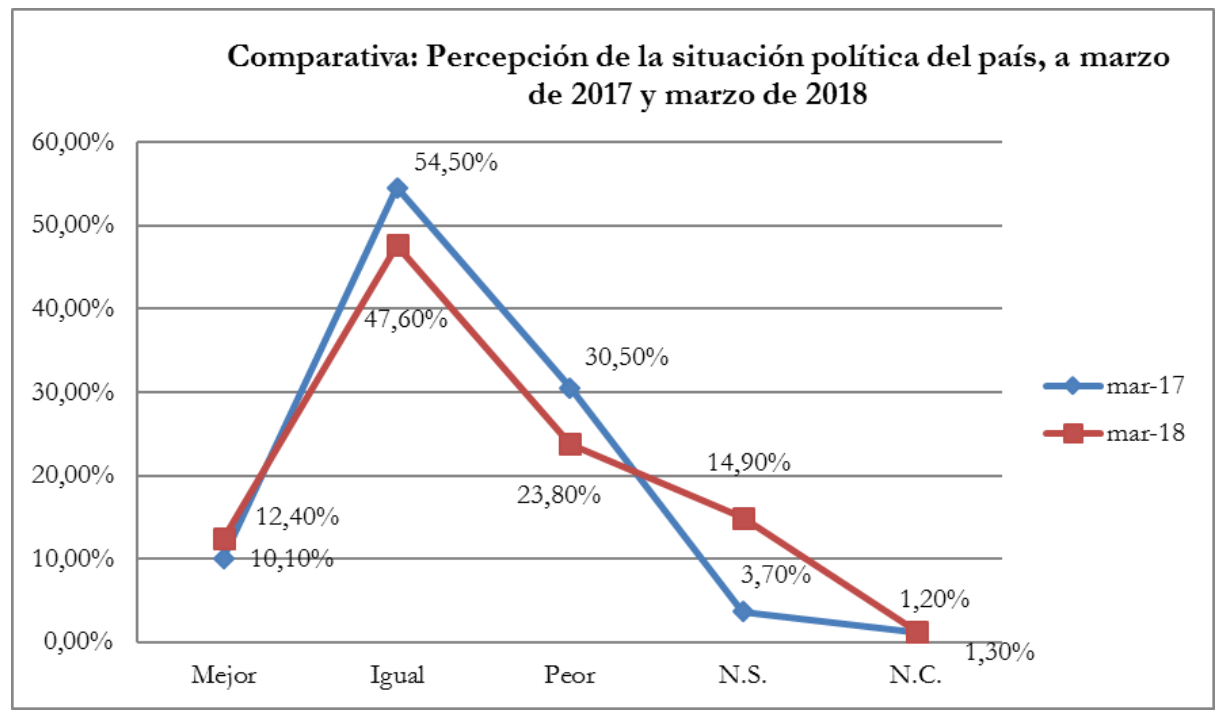

Por ello, ahora más que nunca, la gestión de la reputación y la confianza se convierten en herramientas con un enorme valor intangible para los partidos políticos. De hecho, la doctrina constata un gap importante entre la investigación de la reputación como intangible en el sector privado y la de esta en el sector público, confiriéndole un importante peso específico en el proceso de construcción del liderazgo político (Luoma-aho, 2007 y 2008) ${ }^{36}$. En especial, si nos atenemos a los datos concretos que, una vez más, nos muestran las encuestas del CIS del mes de enero, relativas a la valoración de los líderes políticos. En respuesta a la pregunta: ¿Qué valoración le merece la actuación política de los líderes políticos españoles?, ninguno de ellos alcanza ni tan siquiera el aprobado, como podemos apreciar en el gráfico número $12 .{ }^{37}$ 
Gráfico 13. Fuente: Elaboración propia, a partir del Barómetro del CIS, de Enero de $2017^{38}$

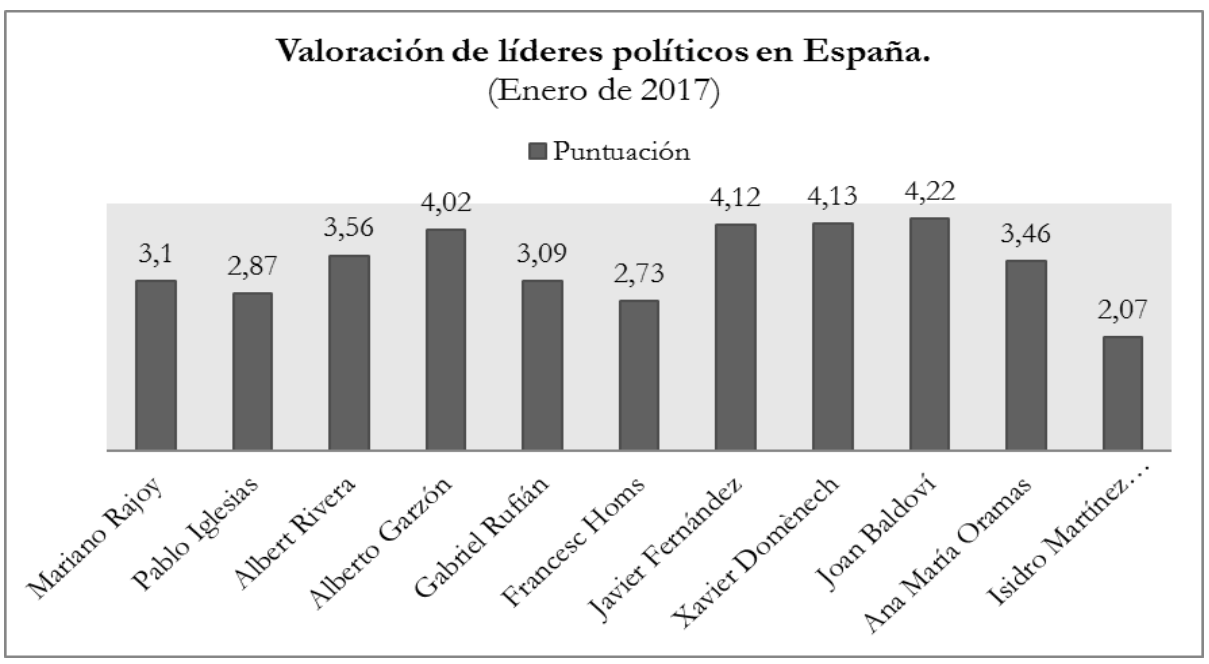

Todo ello, sumado a la crisis política y financiera y los escándalos en organizaciones políticas de todo el mundo, tal como argumentan Cueto Pérez (2014: 1053-1058) y Álvarez (2010: 11), han llevado a la población a una desconfianza generalizada, que empuja a los partidos políticos a demostrar con transparencia, integridad y apertura -como estrategias de gobierno abierto y relacional- que sus prácticas están dentro de la ética que esperan sus votantes, sus afiliados, sus propios integrantes y la sociedad en general.

En especial, aquellos partidos políticos con responsabilidad de gobierno, como es en este caso el Partido Popular español ${ }^{39}$. Una cuestión que es, además, especialmente urgente si tenemos en cuenta la opinión pública contenida en los datos del barómetro del CIS del mes de enero.

En respuesta a la pregunta "En su conjunto, ¿cómo calificaría Ud. la gestión que está haciendo el Gobierno del PP: muy buena, buena, regular, mala o muy mala?", un $83 \%$ del total de encuestados (2.490) subraya la gestión del Gobierno del PP como "regular", "mala" o "muy mala". De forma pormenorizada, la mayoría de los encuestados (el 31,2\%) la califica de "regular". Seguida del 26,1\%, que opina que es "mala", y un 25,7\% que piensa que es "muy mala". 
Gráfico 14. Fuente: Elaboración propia, a partir del Barómetro del CIS, de Enero de $2017^{40}$

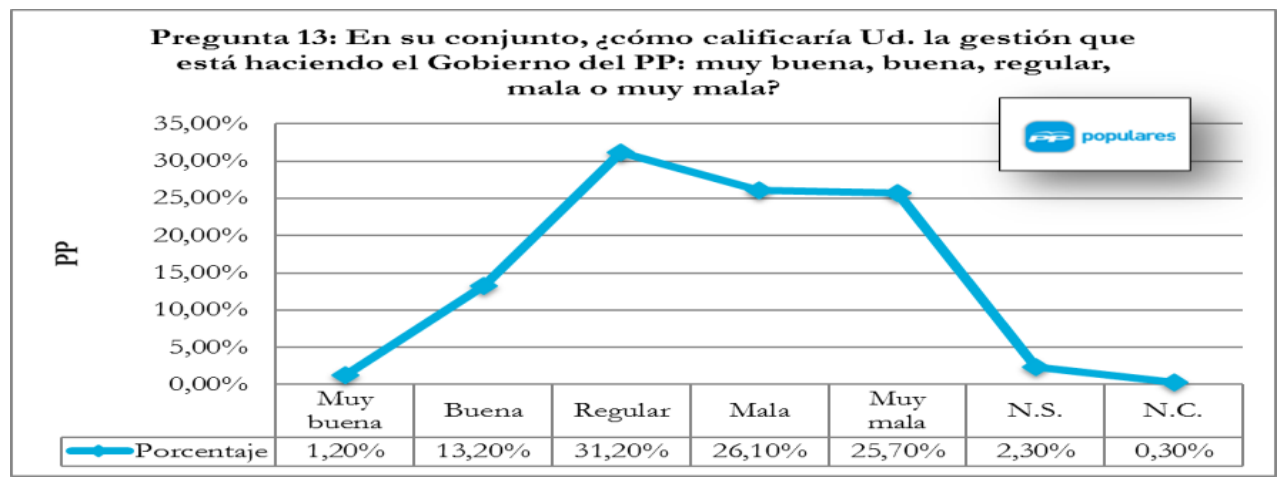

Por su parte, el PSOE, como principal partido en la oposición, tampoco sale mejor parado. Un 91,1\% de los encuestados opina que la actuación política de este partido en la oposición es "regular", "mala" o "muy mala". Específicamente, la califica de "regular" un 28\%, de "mala" un 36,9\% (la mayoría, de un total de 2.490) y de "muy mala" un $26,2 \%$.

Gráfico 15. Fuente: Elaboración propia, a partir del Barómetro del CIS, de Enero de $2017^{41}$

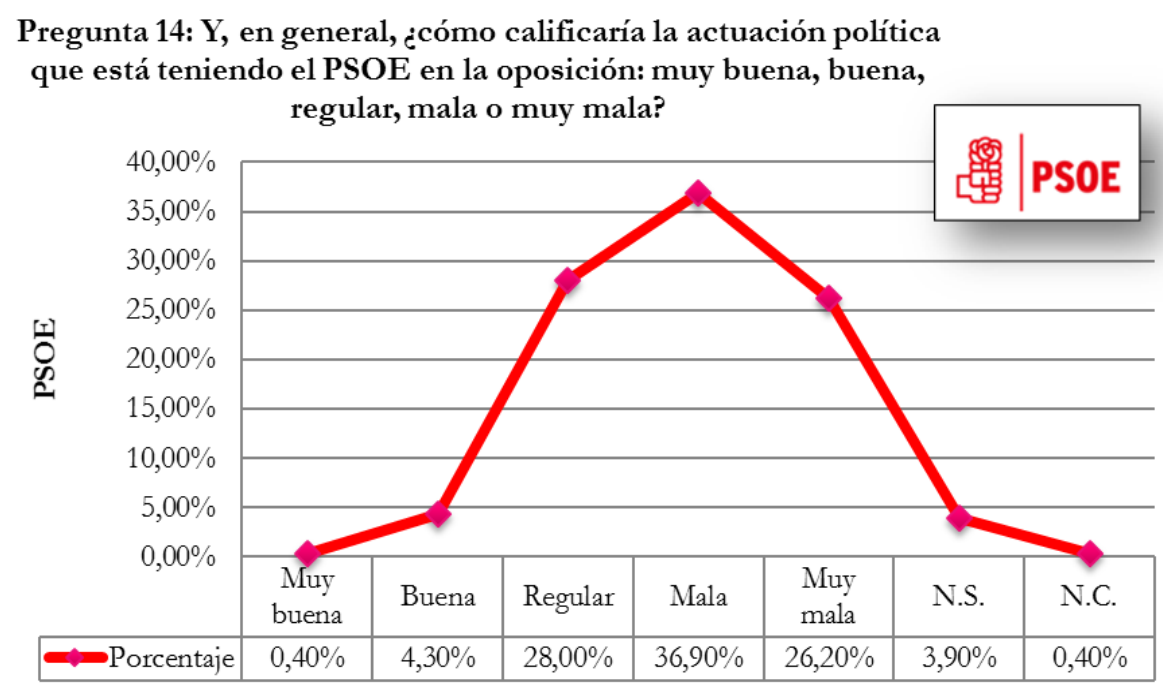


A continuación, y en base a estos resultados, nos podríamos preguntar: ¿cómo se podrían extrapolar, en torno a la generación de confianza hacia nuestros principales líderes políticos, en especial hacia la figura del Presidente del Ejecutivo español? Pues bien, en respuesta a si el Presidente del Gobierno, Mariano Rajoy, inspira, personalmente mucha confianza, bastante confianza, poca o ninguna confianza, la mayoría (el $45,8 \%$, de un total de una muestra de 2.490) opina que el Presidente no le inspira "ninguna confianza". "Poca confianza", un 29,9\%; "bastante confianza, un 16,8\%, y mucha confianza", tan solo un $4,7 \%$.

Gráfico 16. Fuente: Elaboración propia, a partir del Barómetro del CIS, de Enero de 2017

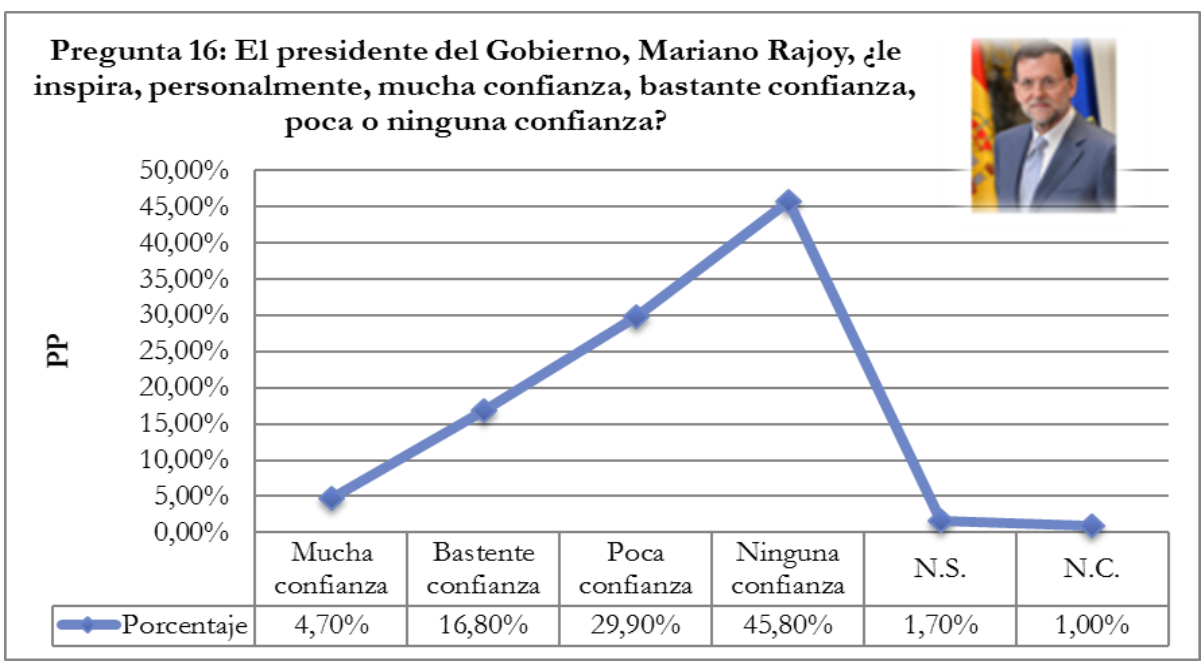

En relación a la valoración de los ministros que conforman el Gobierno de España, tampoco ninguno de ellos alcanza el aprobado. Así se evidencia cuando se pide a los encuestados del barómetro del CIS del mes de enero de 2017 que los valoren en una escala del 0 a $10^{43}$.

Si bien las puntuaciones obtenidas son bajas, los/as ministros/as que obtienen una mejor puntuación - de mayor a menor- son Soraya Sáenz de Santamaría, vicepresidenta y ministra de la Presidencia y para las Administraciones Territoriales- (3,71), Isabel García Tejerina, -ministra de Agricultura y Pesca, Alimentación y Medio Ambiente- (3,3), Íñigo Méndez de Vigo, -ministro de Educación, Cultura y Deporte- $(3,25)$ y Juan Ignacio Zoido, -ministro del Interior- $(3,13)$. El ministro que obtiene la puntuación más baja es Cristóbal Montoro, -ministro de Hacienda y Función Pública- $(2,32)$. 
Gráfico 17. Fuente: Elaboración propia, a partir del Barómetro del CIS, de Enero de $2017^{44}$

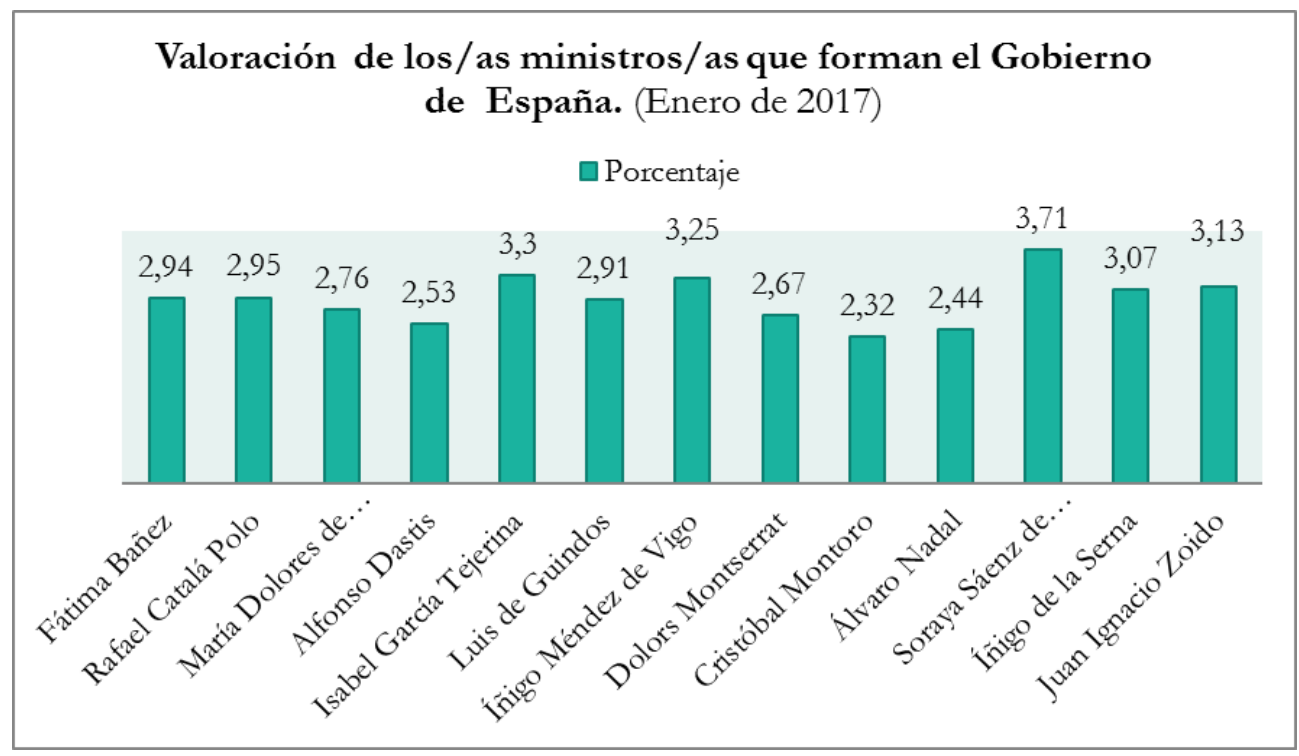

\section{Discusión en torno a algunas propuestas de cambio}

Llegados a este punto, nos preguntamos si la hipótesis de partida del presente trabajo de investigación puede ser validada o, por el contrario, ha de ser refutada. Por ello, tratamos de encontrar respuestas a los siguientes interrogantes: ¿sigue vigente el concepto de "modernidad líquida" propuesto por Bauman, en sus mismos términos y alcance? ¿Puede esta ser considerada, por tanto, un motor de cambio? Todo ello, pese a evidenciar el debilitamiento de los vínculos humanos y encomendar como tarea vital del sujeto la búsqueda de su identidad. Una identidad flexible y versátil que le permita enfrentarse a distintas situaciones a lo largo de su vida.

La respuesta es más que evidente y afirmativa para muchos autores, opinión que compartimos. En especial si esta premisa la extrapolamos a la arena política.

Fundamentalmente, porque la actual sociedad -líquida, compleja y cambiante-, ha sido un caldo de cultivo fértil para la reciente crisis económica mundial que apenas han comenzado a remontar los países desarrollados. Una crisis que ha impactado duramente no solo en la comunidad social y en la propia ciudadanía, sino también en el juicio de los ciudadanos sobre sus 
representantes políticos, poniendo a prueba la solidez y consistencia de las instituciones democráticas (Canel y García Molero, 2013: 29-30). En especial, por su falta de integridad y su escasa eficacia en la gestión de la res publica (Da Silva y Batista, 2007: 592), tal y como hemos tenido oportunidad de evidenciar tras el análisis de los barómetros del CIS más recientes.

Por ello, no son pocos los autores que proponen una estrategia del cambio que, perfectamente, puede ser complementaria a las tesis de Bauman. Las cuales adolecen de un profundo pesimismo en torno a las posibilidades reales al servicio de una "sociedad líquida" para poder salir de su ostracismo y volubilidad.

En este sentido, dicha estrategia deberá enfocarse, al menos, en cuatro retos capitales, claves para que se produzca una auténtica transformación política y social y, por ende, una renovación del liderazgo reputacional, junto a la implementación de mayores dosis de transparencia en la gestión de las políticas públicas de Estado. En especial, si tenemos en cuenta los resultados recientemente obtenidos.

Consecución del compromiso real de los partidos políticos con la gestión pública y la generación de una cultura de confianza por parte de la ciudadanía.

Sin duda, este es el primer reto a conseguir, con la creación de nuevos escenarios basados en la confianza ciudadana, donde se puedan tomar decisiones siguiendo los principios de un gobierno abierto y relacional. Donde todos y cada uno de sus actores apuesten por crear un auténtico valor democrático y no solo beneficios para el representante político en cuestión. Pues, coincidiendo con la tesis de Marcos (2015: 19), "una mayor orientación hacia un fin socialmente responsable es una forma probada de comprometer a las personas", al igual que ocurre en el ámbito del management ${ }^{45}$.

\section{Desarrollo del liderazgo reputacional.}

Este constituye el segundo de los retos a conseguir, ubicado justo en el extremo contrario al liderazgo político tradicional (Boyatzis, 2008: 162; Covey, 1993: 41). Con este fin, los representantes de los partidos políticos (cargos electos o no), y en especial a sus máximos dirigentes, deben prepararse para afrontar los retos del futuro, en detrimento de los del pasado. Han de enfocarse en el diseño de programas sobre gestión pública que garanticen un profundo conocimiento y visión de las perspectivas, necesidades y el contexto actual de la ciudadanía, no solo desde el punto de vista de las élites políticas, adquiriendo una sólida formación en disciplinas complementarias como son la comunicación, el coaching y el marketing político. 


\section{Gestión del cambio y reasignación de roles políticos.}

El tercer reto ha de estar centrado en la gestión eficiente del cambio y en el reposicionamiento del rol del representante político, dentro de su propio partido y en la sociedad (Villoria, 2015: 9). Porque este debe desempeñar un nuevo papel en el marco de una colectividad que reclama -cada vez de forma más urgente- un nuevo modelo de liderazgo e innovadoras fórmulas en el Policy Making Process.

Por ello, este ha de ser un instrumento al servicio de la ciudadanía y no de la cúpula de su partido. Un contrapeso y un punto de apoyo y equilibrio entre la sociedad y el partido al que pertenece (Subirats y Vallespín, 2015: 67). Saliendo de la zona de confort que representa la barrera de un cargo político y el mero cumplimiento de las instrucciones recibidas por la cúpula de su partido.

\section{Modificación de la percepción social sobre los representantes políticos como cargos vitalicios.}

A través de este cuarto reto se pretende construir un nuevo modelo de percepción hacia la figura de "los políticos", quienes a través de las denominadas "puertas giratorias" perpetúan su puesto en un determinado partido (De la Nuez, 2016: 295), precisamente por estar anclados a sus cargos vitalicios.

La nueva percepción ha de ser la de un representante político de valor, al servicio de la ciudadanía, capaz de regenerar la democracia a través de principios como la transparencia, la responsabilidad, la cercanía y la coherencia.

Estos baluartes no solo deben estar a disposición de su propio partido -como ventaja competitiva y diferenciadora de otros en la carrera electoral- sino para la sociedad en su conjunto. Pero, para ello, y tal y como propone Llera Ramo (2016), es necesaria una adecuada configuración de la estrategia de cargos, temporales y no renovables.

Con este fin, es necesario realizar inversiones tanto en los procesos hard como en los soft, para generar confianza, compromiso y -por qué no- creatividad a la hora de crear nuevos modelos de gestión política. De esta forma, los representantes políticos podrán adaptarse mejor a las necesidades del futuro y revertir la desafección política del presente. Sin embargo, para lograr este reto, deberán hacer gala de un mayor liderazgo intelectual en el proceso de generación de estrategias y un mayor desapego a la idea del cargo vitalicio per $s e^{46}$. 


\section{Combatir la corrupción política.}

Este último hecho tiene un claro reflejo en el fenómeno de la corrupción, dado que -como destacan los estudiosos del tema- es mucho más fácil que se desarrollen prácticas corruptas entre políticos que llevan mucho tiempo ocupando un determinado cargo político y que, por añadidura, ostentan responsabilidades de gobierno.

De forma paralela algunos autores, como Ramió (2016) y Moreno (2017) defienden además que la corrupción no posee una naturaleza solo de carácter político vinculada a los partidos y a sus dirigentes, sino que tiene un alcance mucho más transversal, alcanzando al tejido empresarial, a los sindicatos, a los medios de comunicación y a buena parte de la sociedad. Y que tampoco resulta ajena a las administraciones públicas y a sus empleados. Los cuales no han podido frenar o neutralizar las "perversas dinámicas que han contribuido a precarizar a las propias instituciones públicas españolas". Como "subproducto de la propia política española" constituye un reflejo de la ética y de la moral de la sociedad española.

Por todo ello, coincidimos en la necesidad de arbitrar un conjunto de medidas o propuestas para reconducir las patologías causadas por esta lacra en el sistema democrático español y atajar las prácticas corruptas, mediante una intensa regeneración política e institucional, actualmente cristalizadas fruto del elevado nivel de ostracismo político.

En esta línea, y coincidiendo con Ramió (2016), será necesario implementar un exhaustivo elenco de medidas correctoras.

Entre ellas, en primer lugar: el cambio de la Ley Electoral por otra más proporcional; la mejora de la financiación pública de los partidos políticos, reduciendo las aportaciones privadas-; una mayor transparencia y rendición de cuentas total de los partidos políticos y de los sindicatos como si fueran administraciones públicas; la creación de comisiones de supervisión de los cargos políticos; relevo de los máximos líderes políticos de los partidos tradicionales y reconocimiento público de sus casos de corrupción; despolitización de los órganos superiores del poder judicial; mejoras procesales y aumento de recursos en la persecución de la corrupción; así como el diseño de una agencia pública independiente de vigilancia y control de todas las contrataciones del sector público.

En segundo lugar, y el relación a gestión de las políticas públicas de Estado, también será recurrente implementar: una información clara y transparente de los gastos públicos; una evaluación efectiva de las políticas públicas; la puesta 
en vigor de una contabilidad analítica para el cálculo y comunicación de los costes reales de las diferentes actividades y servicios públicos; una dotación de sistemas de información que permitan cruzar bases de datos; una promoción más profunda de los open data y big data para dotar de más inteligencia prospectiva y calidad de gestión a la Administración Pública; así como mejoras tecnológicas de mecanismos de control internos y externos sin exceso de burocracia, entre otras medidas (Cruz-Rubio, 2014).

\section{Fomentar la transparencia como principio democrático.}

Porque, sin duda, la transparencia es la herramienta esencial para el control ciudadano sobre el propio funcionamiento del Estado, de los partidos elegidos democráticamente y de la gestión pública, en especial para el control de la corrupción, por su incidencia en la generación de canales de participación y en la identificación de deficiencias de los sectores públicos que pueden generar oportunidades para eliminar prácticas corruptas (Baena y Vieyra, 2011).

Por ello, se han de fomentar mecanismos que posibiliten, en primer lugar, una auditoría permanente de la gestión pública de los gobernantes, mediante el libre acceso a la información sobre la gestión pública del Estado por parte de la ciudadanía, quienes pasan a convertirse en propietarios de una cuota del patrimonio público (Fuenmayor, 2004). Y, en segundo lugar, la divulgación de información sobre las instituciones que son relevantes para la evaluación de los organismos donde es urgente hacer más transparente su gestión pública, lo cual implica favorecer una rendición de cuentas a la ciudadanía (Ontiveros, 2004), como ya hemos subrayado más arriba.

Como resultado, la transparencia se transforma en un derecho fundamental de los individuos, que no solo permite la participación ciudadana en los asuntos públicos por medio del ejercicio informado de los derechos políticos, sino también de los derechos humanos de los grupos más vulnerables, por lo que los Estados se convierten en sus garantes primigenios.

Por tanto, para configurar este futuro es necesario desarrollar la necesaria voluntad de cambio, fomentar la transparencia y el liderazgo reputacional, para poder responder a las transformaciones globales que están aconteciendo en el marco de la "modernidad líquida" del siglo XXI. Un proceso en el que el ciudadano pueda y deba jugar un papel mucho más activo y protagonista, trabajando junto a partidos políticos e instituciones democráticas para idear estrategias, integrar políticas responsables y comprometer a los partidos y a sus representantes con los valores y objetivos de la sociedad. 


\section{Conclusiones}

Como principal aportación de este trabajo, podemos confirmar la vigencia de los postulados de Bauman. Si bien con algunos matices, en base a los resultados objetivos que hemos obtenido a través del análisis cuantitativo y cualitativo realizado, y que mostraremos a continuación de forma resumida.

Con este fin, hemos tratado de mostrar el retrato de una sociedad "postmoderna". Una sociedad "líquida" que siente lo identitario, pero no lo ve de forma trágica. Si bien todavía mantiene una preocupación por el bienestar económico y una gran desafección no solo hacia la política, sino también hacia las ideologías tradicionales. Esta es, sin duda, la primera conclusión a la que podemos llegar a la luz de los resultados obtenidos.

Por lo tanto, la sociedad líquida en la que cohabitamos ha dejado de vibrar con el "discurso del cambio", se ha desmovilizado, fruto en gran medida del cansancio por las altas cifras del paro, el fraude y la corrupción política, los problemas de índole económica y social, y los políticos y los partidos. Todo ello motivado por la profunda devaluación de la política -desde el inicio de la crisis económica- y el reciente historial de incapacidad para alcanzar acuerdos.

Como resultado, se ha producido una ruptura progresiva del bipartidismo imperante desde la puesta en marcha de la actual democracia en España, situando al votante español en un espectro ideológico de centro-moderado. Ello ha hecho perder fuerza a aquellas posiciones que se situaban en los extremos más antagónicos.

Por todo ello, y coincidiendo con Rosanvallon (2010), la legitimidad tradicional por elecciones y por resultados está en crisis. Por lo que las democracias actuales demandan nuevos tipos de legitimidad. Entre ellas, la legitimidad de imparcialidad, de reflexividad (en torno al papel de tecnócratas y juristas) y de proximidad. Las dos primeras, podrán ser provistas por los órganos de rendición de cuentas horizontal y las burocracias meritocráticas. La de proximidad, por su parte, a por una sociedad civil más activa, que establezca nuevas fórmulas de participación y cooperación directa con la administración.

Sin embargo, en el marco de esta "modernidad líquida", en unos tiempos en los que se han desarrollado profundos sentimientos soberanistas, -al mismo tiempo que determinadas gestiones sobre políticas públicas han desacreditado la existencia de los gobiernos autonómicos-, el modelo de Estado existente 
mantiene su solidez entre los españoles. La mayoría de la ciudadanía no quiere cambios.

Como resultado de la devaluación de la política, el indicador relativo a la percepción de la "situación política" del país ha caído en picado, alcanzando las cifras más bajas de toda la década en 2015, desde el comienzo de la crisis financiera internacional. En especial a partir del año 2008. También se ha producido un descenso muy significativo en los indicadores de "confianza política” (que alcanzó su mínimo histórico en 2013). Así como en el de "expectativas" (cuyos mínimos también tuvieron lugar en dicho año).

Este balance, sumado a la crisis política y financiera y los escándalos en organizaciones políticas de todo el mundo, han llevado a la población a una desconfianza generalizada, que empuja a los partidos políticos a demostrar con transparencia, integridad y apertura -como estrategias de gobierno abierto y relacional- que sus prácticas están dentro de la ética que esperan sus votantes, sus afiliados, sus propios integrantes y la sociedad en general.

Por ello es necesario que, inmerso esta sociedad líquida, el país refuerce su órganos de control, haciéndolos más fuertes e independientes (Intervenciones, Tribunales de Cuentas, Oficinas de Auditoría, Defensorías del Pueblo, Tribunal Constitucional, Consejos de Trasparencia, Oficinas Presupuestarias, o Autoridades Fiscales, entre otras) (Villoria, 2015: 3). De esta forma, los poderes públicos no solo podrán combatir la corrupción sirviéndose de herramientas más eficientes, sino que lograrán un funcionamiento más responsable y eficiente de la gestión pública, potenciando su "responsividad".

Como resultado, la transformación de la democracia en España no se debería hacer esperar, si consideramos los datos analizados, relativos a las cuestiones que más preocupan a la ciudadanía española.

Así pues, todos los resultados de la investigación nos llevan a la conclusión de que una adecuada gestión del liderazgo ha de empezar a formar parte de la lista de prioridades de los partidos políticos de corte tradicional. Junto a esta, la meta de crear valor democrático y una reputación positiva se sitúa ya en el epicentro no solo del debate, sino de la agenda política. Por lo que transparencia y la gestión del riesgo reputacional se han de convertir en prioridades estratégicas para salir de la crisis política e institucional en la que la sociedad española está inmersa.

Por ello, ahora más que nunca, la gestión de la reputación y la confianza se convierten en herramientas con un enorme valor intangible para los partidos 
políticos. Muchas organizaciones -públicas y privadas- han entendido que esto solo será posible si son capaces de proyectar una imagen que atraiga perfiles políticos éticos, creíbles y responsables en nuevos escenarios políticos. Perfiles que no solo deben orientarse a la creación de valor para el votante potencial, sino en el conjunto del entorno político, social y económico, y en el largo plazo.

En este escenario, la "modernidad líquida" deja entrever la importancia de establecer una brecha entre "lo sólido" y "lo líquido". Donde, precisamente por su rigidez y su estancamiento, lo sólido (como metáfora aplicable a las políticas públicas de Estado) debe derretirse y transformarse para dar paso a un modelo más "líquido" de gestión pública, más orientado a la transparencia y hacia la flexibilidad, a la innovación sustentada en infinitas posibilidades aptas para promover unos nuevos modelos de gestión del liderazgo reputacional de los gobiernos y los partidos políticos contemporáneos. En un escenario donde los líderes políticos han de equilibrar intereses, recursos públicos y privados y capacidad de actuación, como responsables directos de su éxito o su fracaso político y, por ende, del propio triunfo o fracaso de la democracia en España y en Europa.

\section{7.-Bibliografía}

Aguilera, M. (2014). La ciudadanía está asqueada, en La corrupción en España. Crítica, no 989 , Madrid, enero-febrero, p. 3.

Beck, U. (1998). La sociedad del riesgo: hacia una nueva modernidad. Barcelona: Paidós.

Bellucci, P., Sanders, D., Tóka, G., y Torcal, M. (2012). Introduction: Antecedents and consequences of European citizenship. En D. Sanders, P. Bellucci, G. Tóka, \& M. Torcal (Eds.), The Europeanization of national policies? Citizenship support in a post-enlargement union. Oxford: Oxford University Press, pp. 1-16.

Borghi, F. (2007). Tipificación del "otro" en el espaciamiento cognitivo de la Modernidad líquida según Zygmunt Bauman. Astrolabio Nueva Época: Revista Digital del Centro de Investigaciones y Estudios sobre Cultura y Sociedad. $n^{\circ} 4$, julio.

Boyatzis, R. (2008). Lider Emocional. Barcelona: Instituto para la Cultura y las Artes. 
Campos, J. E y Pradhan, S. (Eds.) (2009). Las múltiples caras de la corrupción. Aspectos vulnerables por sectores. Banco Mundial. Colombia: Mayol Ediciones.

Canel, M. J. y García Molero, A., (2013). Comunicar gobiernos fiables. Análisis de la confianza como valor intangible del Gobierno de España. Zer, Revista de Estudios de Comunicación, no 18, vol. 34, pp. 29-32.

Covey, S. (1993). Liderazgo centrado en principios. Barcelona: Paidós Ibérica.

Cruz Rubio, C. (2014). Hacia el gobierno abierto: Una caja de herramientas. Washington: Organización de los Estados Americanos (OEA).

Da Silva, R. y Batista, L. (2007). Boosting government reputation through CRM. International Journal of Public Sector Management, $\mathrm{n}^{\circ}$ 7, vol. 20, pp. 588-607.

De la Nuez, E. (2016). El fenómeno de las puertas giratoria”. Eunomia, nº 10, abril-septiembre, pp. 294-296.

Lahera Parada, E. (2004). Política y políticas públicas. Santiago de Chile: Naciones Unidas, Comisión Económica para América Latina y el Caribe (CEPAL).

- (2008). Introducción a las Políticas públicas. Colección Brevarios, $\mathrm{n}^{\circ}$ 538. Santiago de Chile: Fondo de Cultura Económica, 2ª edición.

Llera Ramo, F.J. (coord.), (2016). Desafección política y regeneración democrática en la España actual: diagnósticos y propuestas. Madrid: Centro de Estudios Políticos y Constitucionales.

Luoma-aho, V. (2007). Neutral Reputation and Public Sector Organizations. Corporate Reputation Review, no 10, vol. 2, pp. 124-143.

- (2008). Sector Reputation and Public Organizations. International Journal of Public Sector Management, no 21, vol. 5, pp. 446-467.

Marcos, S. (2015). Gestión del cambio. Capital Humano, no 299, junio, pp. 1820.

Moreno, L. (2017). Recensión sobre el libro de Ramió, C. (2016). La renovación de la función pública. Estrategias para frenar la corrupción política en España. Madrid: La Catarata. En Revista Española de Investigación Sociológica, REIS, no 158, abriljunio, pp. 149-166.

Norris, P. (Ed.), (1999). Critical citizens: Global support for democratic government. Oxford: Oxford University Press. 
Ordóñez, V. y Sanz, V. (2013) Rethinking Democracy, Rethinking State: a Conversation with Zygmunt Bauman. Recerca, n 13 , pp. 171-182.

Pharr, S. J. y Putnam, R. D. (2000) Disaffected Democracies. Princeton: Princeton University Press.

Ramió Matas, C. (2015). Administración Pública y crisis institucional. Estrategias de reforma e innovación para España y América Latina. Madrid: Editorial Tecnos.

Ramírez-Alujas, A. (2011). Sobre la Aplicación y Desarrollo del Concepto de Innovación en el Sector Público: Estado del Arte, Alcances y Perspectivas. Revista Circunstancia, Año IX, nº 26, septiembre, pp. 1-36.

Rosanvallon, P. (2010). La legitimidad democrática: Imparcialidad, reflexividad, proximidad. Barcelona: Paidós.

Sloterdijk, P. (2005). Esferas III. Espumas. Barcelona: Editorial Siruela.

Subirats, J. y Vallespín, F. (2015). España / Reset. Herramientas para un cambio de sistema. Barcelona: Ariel.

Torcal, M. (2014). The Decline of Political Trust in Spain and Portugal: Economic Performance or Political Responsiveness?. American Behavioral Scientist, no 12 , vol. 58, pp. 1657-1682.

Vera Silva, A. A. (coord.) (2015). Microrrelatos. 100 palabras Zygmunt Bauman. Colombia: Universidad Autónoma de Bucamaranga.

Villoria, M. (2015). Desafección política y gobierno abierto: Relaciones y limitaciones. XX Congreso Internacional del Clad, Lima (Perú), noviembre, pp. 128.

Villoria, M. y Jiménez, F. (2014). Estado de derecho, cultura de la legalidad y buena gobernanza. En I. Wences, R. Conde y A. Bonilla (Coords). Cultura de la legalidad en Iberoamérica: desafíos y experiencia. Costa Rica: FLACSO, pp. 83-118.

Villoria, M., Jiménez, F. y Revuelta, A. (2014). Corruption Perception and Collective Action: The Case of Spain. En J. Mendilow e I. Peleg. Corruption in the Contemporary World: Theory, Practice and Hotspots. Maryland: Lexington Books, pp. 197-222 
Villoria, M., Gegg Van Ryzin, G. y Lavena, C. (2013). Social consequences of government corruption: A study of institutional disaffection in Spain. Public Administration Review (PAR), n 1, vol. 73, enero-febrero, pp. 85-94.

Zygmunt, B. (1999). In Search of Politics. Cambridge: Polity Press.

- y Tester, K. (2001).Conversations with Zygmunt Bauman. Cambridge: Polity Press.

- (2001). The Individualized Society. Cambridge: Polity Press.

- (2003). Comunidad. Argentina: Siglo XXI.

- (2004). Ética postmoderna. Argentina: Siglo XXI.

- (2005). Vidas desperdiciadas. La modernidad y sus parias. Buenos Aires: Paidós.

- (2007a). Miedo líquido. La sociedad contemporánea y sus temores. Barcelona: Paidós.

- (2007b). Liquid Times: Living in an Age of Uncertainty. Cambridge: Polity Press.

- (2007c). Consuming Life. Cambridge: Polity Press.

- (2011). Collateral Damage: Social Inequalities in a Global Age. Cambridge: Polity Press.

\section{Notas}

1 Para Zygmunt Bauman, la metáfora de la "Modernidad líquida" representa una figura del cambio y de la transitoriedad, pues "los sólidos conservan su forma y persisten en el tiempo: duran, mientras que los líquidos son informes y se transforman constantemente: fluyen. Como la desregulación, la flexibilización o la liberación de los mercados". Vid. Bauman, Z. (2007b). Liquid Times: Living in an Age of Uncertainty. Cambridge: Polity Press, p.7. En este sentido, los líquidos son informes y se transforman constantemente, fluyendo. Por eso la metáfora de la liquidez es la adecuada para aprehender la naturaleza de la fase actual de la modernidad y la gestión actual de las políticas públicas en España y en Europa. No hay pautas estables ni predeterminadas en esta versión privatizada de la modernidad. Para ofrecernos sus claves, y desde la base científica de la sociología, Bauman examina cinco conceptos básicos en torno a los cuales ha girado la narrativa de la condición humana: emancipación, individualidad, tiempo/espacio, trabajo y comunidad.

2 Traducido al español: "La democracia es ya una ficción, porque la idea de democracia estaba basada en la idea de la soberanía nacional". El texto completo puede ser consultado en Ordóñez, V. y Sanz, V. (2013) Rethinking Democracy, Rethinking State: a Conversation with Zygmunt Bauman, Recerca, no 13, p. 176.

${ }^{3}$ Citado en Vásquez Rocca, A. (2008). Zygmunt Bauman: Modernidad Líquida y Fragilidad Humana. Nómadas. Revista Crítica de Ciencias Sociales y Jurídicas, $\mathrm{n}^{\circ} 19$. Universidad Complutense de Madrid, pp. 309-316, específicamente, en p. 312. Véase, asimismo, del mismo autor: (2007). Peter Sloterdijk; espumas, mundo poliesférico y ciencia amplia de invernaderos. Konvergencias. Revista de Filosofía y Culturas en Diálogo, no 16. Capital Federal, Argentina, pp. 217-228. 
${ }^{4}$ Lahera afirma que las políticas públicas "son un factor común de la política y de las decisiones de gobierno y de la oposición". De esta forma, puede ser analizada "como la búsqueda de establecer o bloquear políticas públicas sobre determinados temas, o de influir en ellas". A su vez, gran parte del quehacer del gobierno está centrado en su diseño, gestión y evaluación. Vid. Lahera, E. (2004). Política y políticas públicas. Santiago de Chile: Naciones Unidas, Comisión Económica para América Latina y el Caribe (CEPAL), p. 7.

${ }^{5}$ Véase http://www.cis.es/cis/opencms/ES/11 barometros/metodologia.html

${ }^{6}$ Para aquellos que son medibles a través de una variable cuantitativa, se utilizan los índices simples, los índices compuestos de Laspeyres o de Paasche, o el índice ideal de Fisher.

${ }^{7}$ En este caso, las variables a las que dan lugar las preguntas suelen ser de tipo cualitativo, con distintas opciones de respuesta. Con carácter general, los resultados se presentarán como los porcentajes de respuesta para cada una de las opciones. Con este fin, se construyen indicadores alternativos que sinteticen en una sola cifra toda la información. Lo cual suele hacerse, por ejemplo, calculando números índices o saldos de respuestas, por analogía con el caso de las variables cuantitativas.

${ }^{8}$ Véase CIS, Centro de Investigaciones Sociológicas: Barómetros, Metodología.

Recuperado

de:

http://www.cis.es/cis/opencms/ES/11 barometros/metodologia.html [fecha de consulta: 12/02/2017].

${ }^{9}$ Incluyen preguntas relativas a este ítem. Por ejemplo:

"P1: Refiriéndonos ahora a la situación económica general de España, ¿cómo la calificaría Ud.: muy buena, buena, regular, mala o muy mala?”. "P2: Y, ¿cree Ud. que dentro de un año la situación económica del país será mejor, igual o peor que ahora?" Se construye el Indicador de la Situación Económica Actual (SEA),

a partir de la pregunta P1 como: $S E A=\frac{100 \cdot p_{1}+75 \cdot p_{2}+50 \cdot p_{3}+25 \cdot p_{4}+0 \cdot p_{5}}{p_{1}+p_{2}+p_{3}+p_{4}+p_{5}}$ donde $\mathrm{p}_{1}, \mathrm{p}_{2}$, $\mathrm{p}_{3}, \mathrm{p}_{4}$ y $\mathrm{p}_{5}$ son, respectivamente, las proporciones de respuesta de las opciones muy buena, buena, regular, mala y muy mala, respectivamente. Análogamente, se construye el Indicador de Expectativas Económicas (IEE) a partir de la pregunta P2 como: $\quad$ IEE $=\frac{100 \cdot p_{1}+50 \cdot p_{2}+0 \cdot p_{3}}{p_{1}+p_{2}+p_{3}}$, donde $\mathrm{p}_{1}, \mathrm{p}_{2}$ y $\mathrm{p}_{3}$ son, respectivamente, las proporciones de respuesta de las opciones mejor, igual y peor, respectivamente. Por último, el Indicador de Confianza Económica (ICE) es la media aritmética de los otros dos: $I C E=\frac{S E A+I E E}{2}$

${ }^{10}$ Para obtener estos indicadores, los barómetros mensuales del CIS responden a preguntas sobre la situación política, totalmente análogas a las relativas a la situación económica. Por ejemplo: "P1:Refiriéndonos ahora a la situación política general de España, ¿cómo la calificaría Ud.: muy buena, buena, regular, mala o muy mala?"; "P2: Y, ¿cree Ud. que dentro de un año la situación política del país será mejor, igual o peor que ahora?”. El Indicador de la Situación Política Actual $(S P A)$, a partir de la pregunta P1 será: 
$S P A=\frac{100 \cdot p_{1}+75 \cdot p_{2}+50 \cdot p_{3}+25 \cdot p_{4}+0 \cdot p_{5}}{p_{1}+p_{2}+p_{3}+p_{4}+p_{5}}$, donde $\mathrm{p}_{1}, \mathrm{p}_{2}, \mathrm{p}_{3}, \mathrm{p}_{4}$ y $\mathrm{p}_{5}$ son, respectivamente, las proporciones de respuesta de las opciones muy buena, buena, regular, mala y muy mala, respectivamente.

El Indicador de Expectativas Políticas (IEP) a partir de la pregunta P2 será: IEP $=\frac{100 \cdot p_{1}+50 \cdot p_{2}+0 \cdot p_{3}}{p_{1}+p_{2}+p_{3}}$, , donde $\mathrm{p}_{1}, \mathrm{p}_{2} \mathrm{y} \mathrm{p}_{3}$ son, respectivamente, las proporciones de respuesta de las opciones mejor, igual y peor, respectivamente.

Por último, el Indicador de Confianza Política $(I C P)$ es la media aritmética de los otros dos: ${ }^{I C P}=\frac{S P A+I E P}{2}$

11 Para considerar estos indicadores, los barómetros del CIS se sirven de preguntas como: "P1: En su conjunto, ¿cómo calificaría Ud. la gestión que está haciendo el gobierno del PSOE: muy buena, buena, regular, mala o muy mala?"; "P2: En su conjunto, ¿cómo calificaría Ud. la gestión que está haciendo el gobierno del PP: muy buena, buena, regular, mala o muy mala?”; "P3: En general, ¿cómo calificaría Ud. la actuación política que está teniendo el PSOE en la oposición: muy buena, buena, regular, mala o muy mala?”; "P4: En general, ¿cómo calificaría Ud. la actuación política que está teniendo el PP en la oposición: muy buena, buena, regular, mala o muy mala?’. En los barómetros del primer mes de cada trimestre desde 1996 se realizan las preguntas P1 y P4 ó P2 y P3 alternativamente, dependiendo de cuál es el partido en el gobierno y cuál es el primer partido de la oposición. A partir de éstas, se construyen, en primer lugar, las series de Valoración de la Labor del Gobierno y Valoración de la labor del Primer Partido de la Oposición simplemente intercalando las preguntas P1 y P2 por un lado, y P3 y P4 por el otro, respectivamente; las cuales evalúan el comportamiento del gobierno y la oposición, independientemente del partido al que pertenezcan sus miembros.

${ }^{12}$ En base a la siguiente fórmula: $I L G=\frac{100 \cdot p_{1}+75 \cdot p_{2}+50 \cdot p_{3}+25 \cdot p_{4}+0 \cdot p_{5}}{p_{1}+p_{2}+p_{3}+p_{4}+p_{5}}$, donde $\mathrm{p}_{1}, \mathrm{p}_{2}$, $\mathrm{p}_{3}, \mathrm{p}_{4}$ y $\mathrm{p}_{5} \mathrm{son}$, respectivamente, las proporciones de respuesta de las opciones muy buena, buena, regular, mala y muy mala, respectivamente, en las preguntas $\mathrm{P} 1$ y $\mathrm{P} 2$.

13 Utilizando la fórmula: $I L O=\frac{100 \cdot p_{1}+75 \cdot p_{2}+50 \cdot p_{3}+25 \cdot p_{4}+0 \cdot p_{5}}{p_{1}+p_{2}+p_{3}+p_{4}+p_{5}}$, donde $\mathrm{p}_{1}, \mathrm{p}_{2}, \mathrm{p}_{3}, \mathrm{p}_{4}$ y $\mathrm{p}_{5}$ son, respectivamente, las proporciones de respuesta de las opciones muy buena, buena, regular, mala y muy mala, respectivamente, en las preguntas P3 y P4. Se construye después el Indicador de Confianza del Sistema Político (ICSP) como la media aritmética de los otros dos: $I C S P=\frac{I L G+I L O}{2}$

${ }^{14}$ Para una predicción más fiable de los resultados electorales, el CIS construye a partir de la Intención de Voto lo que se conoce como "Estimación de Voto". Consiste en aplicar a la Intención de Voto un modelo de corrección basado en otras variables de la encuesta, la experiencia pasada o informaciones de tipo cualitativo. 
15 Para su elaboración, el CIS parte de la pregunta: "Cuando se habla de política se utilizan normalmente las expresiones izquierda y derecha. En esta tarjeta hay una serie de casillas que van de izquierda (con el valor 1) a derecha (con el valor 10). ¿En qué casilla se situaría Ud.?”. A partir de la misma, construye dicho indicador como la media aritmética de las respuestas (eliminando los 'No sabe' y 'No contesta'). También se suele calcular la desviación típica, que se mantiene prácticamente constante, para verificar la validez del cálculo de la media.

${ }^{16}$ En especial, si tenemos en cuenta las últimas encuestas publicadas por el Centro de Investigaciones Sociológicas (CIS), que pueden ser consultadas en su página web: http://www.cis.es/cis/opencms/ES/index.html

$17 \mathrm{Vid}$. Centro de Investigaciones Sociológicas (CIS). Gráfico de la tasa interanual de la autoubicación ideológica media, (1996-2017). Recuperado de: http://www.cis.es/cis/opencms/ES/11_barometros/Indicadores_PI/documento s/tasAubid.html, [fecha de consulta: 17/07/2017].

18 Vid. CIS. Estudio no 3170. Barómetro de Marzo de 2017. Avance de Resultados. Recuperado de: http://www.cis.es/cis/opencms/ES/NoticiasNovedades/InfoCIS/2017/Docum entacion 3170.html. [fecha de consulta: 10/04/2017].

${ }^{19}$ Entendido este término como capacidad de los gobiernos y poderes públicos, en general, de responder oportuna y correctamente frente a una situación determinada. En este caso, frente a un contexto generalizado de crisis económica, financiera, política y social, como la acontecida en fechas recientes en España, Europa y a nivel global.

${ }^{20}$ Ibidem.

${ }^{21}$ Diversos estudios sobre la relación entre corrupción y desconfianza (y sobre los que no profundizaremos) refuerzan esta afirmación. Entre otros, podemos mencionar los de: León, C.J., Araña, J.E. y De León, J. (2013). Valuing the social cost of corruption using subjective well being data and the technique of vignettes. Applied Economics, $\mathrm{n}^{\mathrm{o}}$ 45, pp. 3863-3870; Hodson, G. M. y Jiang, S. (2007). The economics of corruption and the corruption of economics: an institutionalist perspective. Journal of Economic Issues, $\mathrm{n}^{\circ}$ 41, vol. 4, pp. 1043-1061; Bowler, S. y Karp, J.A. (2004). Politicians, scandals, and trust in Government. Political Behavior, $n^{\circ}$ 26, vol. 3, pp. 271-287; Anderson, C. y Tverdova, Y. (2003). Corruption, political allegiances, and attitudes toward government in contemporary democracies. American Journal of Political Science, n ${ }^{\circ}$ 47, pp- 91-109; Pharr, S.J. y Putnam, R.D. (2000). Disaffected Democracies. Princeton: Princeton University Press; y Ades, A. y Di Tella, R. (1997). The New Economics of Corruption: A Survey and Some New Results, en Heywood, P. Political Corruption. Oxford: Blackwell Pub.

22 Vid. Acuerdo de 20 de julio de 2016, de la Junta Electoral Central, por el que se publica el resumen de los resultados de las elecciones al Congreso de los Diputados y al Senado convocadas por Real Decreto 184/2016, de 3 de mayo, y celebradas el 26 de junio de 2016, conforme a las actas de escrutinio general y de proclamación de electos remitidas por las correspondientes Juntas Electorales 
Provinciales y por las Juntas Electorales de Ceuta y de Melilla [BOE núm. 176, Sec. III, de 22 de julio de 2016].

${ }^{23} \mathrm{~V}$ id. CIS. Gráfico de la serie de la estimación de voto en elecciones generales $\mathrm{PP} / \mathrm{PSOE} /$ Podemos/C's, CIS. Estimación de voto en elecciones generales (\%) (1996- 2017). Disponible en: http://www.cis.es/cis/opencms/ES/11_barometros/Indicadores_PI/documento s/B606050020a.html, [fecha de consulta: 17/07/2017].

24 Vid. CIS. Estudio n ${ }^{\circ}$ 3164. Barómetro de Enero de 2017. Disponible en: http://datos.cis.es/pdf/Es3164rei_A.pdf, [fecha de consulta: 03/04/2017].

25 Vid. CIS. Estudio no 3170. Barómetro de Marzo de 2017. Avance de Resultados. Recuperado

de: http://www.cis.es/cis/opencms/ES/NoticiasNovedades/InfoCIS/2017/Docum entacion 3170.html [fecha de consulta: 10/04/2017].

26 Vid. CIS. Estudios no 3124, 3128, 3131, 3134, 3138, 3142, 3146, 3149, 3156, 3159, 3162, 3164, 3168 3170. Barómetros de Enero de 2016 a Marzo de 2017 [Avance de Resultados]. Recuperado de http://www.analisis.cis.es/cisdb.jsp y http://www.cis.es/cis/opencms/ES/NoticiasNovedades/InfoCIS/2017/Docum entacion 3170.html [fecha de consulta: 24/04/2017].

${ }^{27}$ Vid. Campos, J. E y Pradhan, S. (eds.) (2009). Las múltiples caras de la corrupción. Aspectos vulnerables por sectores. Banco Mundial. Colombia: Mayol Ediciones.

28 Todos los informes de la ONG Transparencia Internacional, tales como "El índice de Percepción de la Corrupción (IPC)", "Barómetro Global de la Corrupción (BGC)", o el "Informe Global de la Corrupción (IGC)", pueden ser consultados en su página web http://transparencia.org.es/

29 Disponible en: http://transparencia.org.es/ipc-2016/ [fecha de consulta: 25/04/2017].

30 Véanse los 'Índices de Transparencia en España", relativos a Ayuntamientos, Comunidades Autónomas, Diputaciones, Gestión del Agua, Parlamentos, o Clubes de Fútbol, elaborados por Transparency International España, disponibles en http://transparencia.org.es/indices-transparencia-espana/

31 Por otro lado, los encuestados tampoco parecen mostrar una excesiva inquietud por los recortes realizados por los gobiernos del Partido Popular en sus dos últimas legislaturas en base a los datos obtenidos, que arrojan una media del 2,28\% del total. Ni por el (deficiente) funcionamiento de los servicios públicos, que preocupa tan solo a un $0,37 \%$ de los encuestados.

32 Vid. CIS. Estudios no 3124, 3128, 3131, 3134, 3138, 3142, 3146, 3149, 3156, 3159, 3162, 3164, 3168 3170. Barómetros de Enero de 2016 a Marzo de 2017 [Avance de Resultados]. Recuperado de http://www.analisis.cis.es/cisdb.jsp y http://www.cis.es/cis/opencms/ES/NoticiasNovedades/InfoCIS/2017/Docum entacion 3170.html [fecha de consulta: 24/04/2017].

${ }^{33}$ Recuperado de http://www.cis.es/cis/opencms/ES/11 barometros/Indicadores PI/documento s/serPol.html [fecha de consulta: 24/04/2017].

34 Vid. CIS. Estudio $n^{\circ}$ 3170. Barómetro de Marzo de 2017. Avance de Resultados. Recuperado

de: 
http://www.cis.es/cis/opencms/ES/NoticiasNovedades/InfoCIS/2017/Docum entacion 3170.html [fecha de consulta: 10/04/2017].

${ }^{35}$ Ibidem.

36 Vid. Luoma-aho, V. (2007). Neutral Reputation and Public Sector Organizations. Corporate Reputation Review, no 10, vol. 2, pp. 124-143; y (2008). Sector Reputation and Public Organizations. International Journal of Public Sector Management, $\mathrm{n}^{\mathrm{o}}$ 21, vol. 5, pp. 446-467. Ambos citados en Canel, M. J. y García Molero, A., (2013). Comunicar gobiernos fiables. Análisis de la confianza como valor intangible del Gobierno de España. Zer, Revista de Estudios de Comunicación, $\mathrm{n}^{\circ}$ 18, vol. 34 , p. 32.

${ }^{37}$ La calificación más alta la obtiene Joan Baldoví, -diputado por Valencia en el Congreso de los Diputados de Coalició Compromís- (4,22 puntos), seguido muy de cerca por Xavier Domènech, -Portavoz adjunto del Grupo Confederal UP-ECEM en el Congreso de los Diputados- $(4,13)$ y Xavier Fernández, -Presidente del Principado de Asturias y de la Comisión Gestora del PSOE- (4,12). El que menor puntuación obtiene es Isidro Martínez Oblanca, -Senador por Foro Asturias -(con 2,07 puntos). Tampoco ninguno de los líderes de los partidos más votados en las últimas elecciones generales alcanza el aprobado, ni tan siquiera Mariano Rajoy $(3,1)$, Pablo Iglesias $(2,87)$, o Albert Rivera $(3,56)$.

38 Vid. CIS. Estudio no 3164. Barómetro de Enero de 2017. Recuperado de: http://www.cis.es/cis/opencm/ES/1 encuestas/estudios/ver.jsp?estudio $=14325$ [fecha de consulta: 03/04/2017].

${ }^{39}$ En las pasadas elecciones de 26 de junio de 2016 el partido más votado fue el PP (obteniendo un 33,03\% de los votos), seguido del PSOE (22,66\%), Unidos Podemos (21,10\%), C's (13,05\%), ERC (2,63\%), CDC (2,1\%), EAJ-PNV (1,2\%) y EH-Bildu (0,77\%).

40 Ibidem.

${ }^{41}$ Ibidem.

42 Ibidem.

${ }^{43}$ Sabiendo que el 0 significa que lo/a valora muy mal y el 10 que lo/a valora muy bien.

44 Vid. CIS. Estudio n ${ }^{\circ}$ 3164. Barómetro de Enero de 2017. Recuperado de: http://www.cis.es/cis/opencm/ES/1 encuestas/estudios/ver.jsp?estudio $=14325$ [fecha de consulta: 03/04/2017].

${ }^{45}$ Entre la numerosa doctrina desarrollada sobre este tema, cabe citar la siguiente: Marco Marco, J. y Nicasio Varea, B. (coords.) (2014). La regeneración del sistema: Reflexiones en torno a la calidad democrática, el buen gobierno y la lucha contra la corrupción. Valencia: AVAPOL Asociación Valenciana de Politólogos; Valladolid, A. (2013). La regeneración indispensable. Tiempo, $\mathrm{n}^{\circ}$ 1608, p. 21; Calderón, C. y Lorenzo, S. (coords.) (2010). Open Government. Gobierno Abierto. Madrid: Algón Editores; Ramírez Alujas, Á. (2011). Gobierno Abierto y modernización de la Gestión Pública: Tendencias actuales y el inevitable camino que viene. Reflexiones seminales. Revista Enfoques, n ${ }^{\circ}$ 15, vol. IX, pp. 99-125. Y por otro, aquéllas que abren la posibilidad de la participación ciudadana para controlar e influir en los procesos de gobierno a través del acceso a la información y en la propia escena política, estando presentes en el proceso de toma de decisiones: Meijer, A., Curtin, 
D. y Hillebrandt, M. (2012). Open government: connecting vision and voice. International Review of Administrative Sciences, $\mathrm{n}^{\circ}$ 78, vol. 1, pp. 10-29; y Guardián Orta, C. (2010). ¿Transparencia?, en C. Calderón, y S. Lorenzo (coords.). Open Goverment: Gobierno abierto. (...) op. cit., pp.75-86.

46 Para profundizar en el debate, pueden ser consultados: Del Pozo, J.L. (2016). Una reflexión sobre las "puertas giratorias". Acontecimiento: Órgano de expresión del Instituto Emmanuel Mounier, no 119, pp. 59-61; Betancor Rodríguez, A. (2016). Puertas giratorias: regulación y control, en M. Villoria Mendieta; J.M. Gimeno Feliú; J.C. Tejedor Bielsa y R. Jiménez Asensio. La corrupción en España: ámbitos, causas y remedios jurídicos, Barcelona: Atelier, pp. 157-184; y Navarro, P.A. (2016). Políticos con el futuro en el bolsillo: Un 40 por ciento de los ministros de la democracia, en Consejos de administración. El siglo de Europa, no 1167, 12 de septiembre, pp. 24-30. 


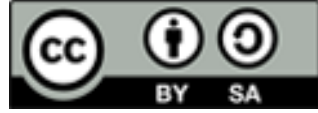

Licencia Creative Commons

Miguel Hernández Communication Journal

mhjournal.org

\section{Cómo citar este texto:}

José Javier Ruiz Cartagena (2017): "Millennials y redes sociales: estrategias para una comunicación de marca efectiva”, en Miguel Hernández Communication Journal, nº, pp. 369 a 411. Universidad Miguel Hernández, UMH (Elche-Alicante). Recuperado el _ de de $20 \_$_e: [link del artículo en mhjournal.org] 
